\title{
Vibration and Deflection Behavior of a Coal Auger Working Mechanism
}

\author{
Songyong Liu, ${ }^{1,2}$ Huifu Ji, ${ }^{1,2}$ and Xinxia Cui ${ }^{1,2}$ \\ ${ }^{1}$ School of Mechatronic Engineering, China University of Mining and Technology, Xuzhou, Jiangsu 221116, China \\ ${ }^{2}$ Jiangsu Key Laboratory of Mine Mechanical and Electrical Equipment, China University of Mining and Technology, \\ Xuzhou, Jiangsu 221116, China
}

Correspondence should be addressed to Huifu Ji; jihuifu890713@126.com

Received 17 July 2015; Accepted 23 November 2015

Academic Editor: Mickaël Lallart

Copyright (c) 2016 Songyong Liu et al. This is an open access article distributed under the Creative Commons Attribution License, which permits unrestricted use, distribution, and reproduction in any medium, provided the original work is properly cited.

\begin{abstract}
Because coal auger working mechanism faces problems such as excessive vibration, serious deflection, and low drilling efficiency, a new five-bit coal auger working mechanism test model was established to explore the influence factor on vibration and deflection under different conditions. Additionally, a simulation model was built to further research the effect of partial load and stabilizer arrangement, the correctness of which was proved by experiments. The results show that the vibration and deflection increase with drilling depth in the $x$ direction, and they first increase and then gradually become stable in the $y$ direction. In addition, the vibration, deflection, and deflection force increase with the partial load. By arranging the stabilizer every five drill-rod section intervals, the vibration and deflection can be decreased by $30 \%$ and $40 \%$ in the $x$ direction and by $14.3 \%$ and $65.7 \%$ in $y$ direction, respectively.
\end{abstract}

\section{Introduction}

The coal auger is a new type of thin seam mining equipment that has good prospects in unmanned and nonsupported coalface mining. Recently, a new type of coal auger working mechanism with five bits was used to improve coal mining efficiency $[1,2]$. The five-bit coal auger is shown in Figure 1. Due to the constraint reaction force of coal wall, gravity, cutting resistance, and friction, the vibration of the working mechanism is relatively excessive, which can cause serious drilling deflection [3]. To solve this issue, simulations and experimental research were conducted to study the vibration and deflection behavior of the working mechanism. Meanwhile, a new stabilizer was deployed to reduce the vibration and deflection.

The working mechanism of coal auger consists of a drill-rod and a vent-tube. As an important component of the working mechanism, the deflection and vibration characteristics of various shapes of drill-rods were studied. A three-dimensional dynamic model of drill-rod was built for studying the influence of drilling pressure, torque, rotating speed, and other parameters of the drilling process, which indicated that the intermittent contact, dynamic torque, and friction have an important influence on the vibration characteristics [4-7]. Considering the gyroscopic effect, the torsional/bending inertia coupling, and the effect of the gravitational force field, a dynamic model of the drillrod including the drill collars was established [8-10]. The transient dynamic model between the drill string and the wall was established for analyzing the interaction among bits, stabilizer, and borehole walls [11]. In the same year, through analyzing the contact model between the drilling mechanism and the borehole walls, the contact model was divided into continuous contact and continuous collisions. The main reason for the drilling deflection was the increase of the borehole diameter [12]. By analyzing vibration characteristics of the drill-rod under different non-Newtonian flow velocities and densities, a piecewise smooth model with three degrees of freedom, which exhibits friction-induced stick-slip oscillations, was considered, which can be used to describe the bit-sticking phenomena $[13,14]$. The drill-rod vibrations with differential quadrature method were analyzed, which 


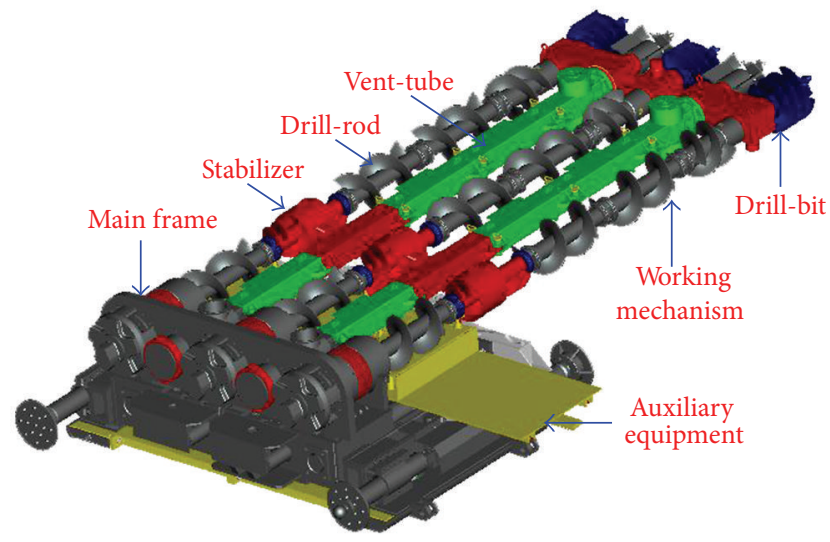

(a)

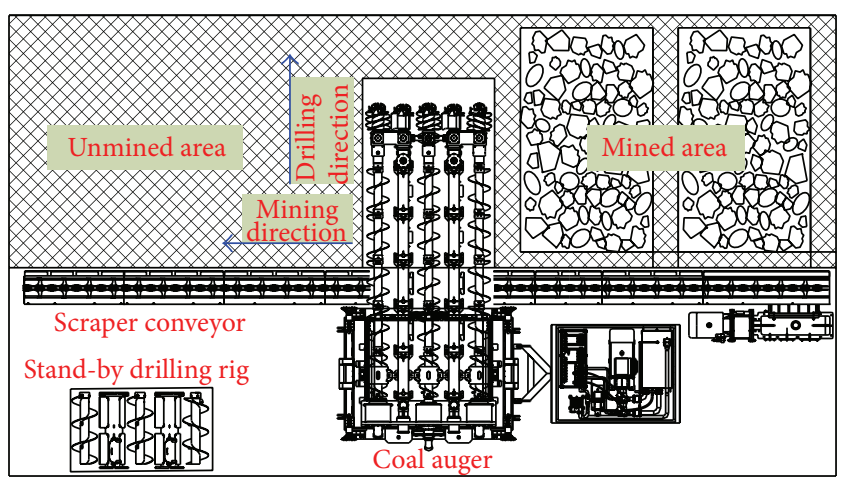

(b)

FIgURE 1: General layout of five-bit coal auger.

indicated the method was efficient and accurate in dealing with the drill-rod vibration problems [15]. To analyze the dynamic stability, critical length, and the vibration characteristics with different boundary conditions and sizes, some relevant measures such as perturbation techniques and extended Lagrange multiplier method were adopted to reduce the drillrod vibration [16-19]. Considering the collision conditions of the drill-rod and rock, the interacted system coupling dynamics model of multidrilling mechanism and rock was built, and vibration was acquired under different compression strength rocks and different rotary speeds of drill [20]. A nonlinear model of axial and torsional coupled vibration of the rotary drill-rod was established. It suggests that adjusting the processing parameter properly contributes to reduce the drill-rod stick-slip vibration and bit bouncing [21]. The stress distribution of the drill-rod worked in soft coal seam was simulated, which shows that the drill-rod joint causes stress concentration [22].

Influence of different boundary conditions, drilling parameters, and drilling load conditions on the working mechanism vibration has been studied in the above articles. However, the vibration characteristics and the deflection behavior of five-bit coal auger under different conditions have not been studied. This restricts the effective vibration and deflection prediction and impedes the application of coal auger. Based on this, a rigid-flexible coupling simulation model of a five-bit working mechanism was established in this paper. Vibration and deflection behavior of the working mechanism under different drilling depths, partial loads, and stabilizer arrangements were studied both by simulation and by experiments to determine the deviation law of the working mechanism. This can provide a reference for controlling the deflection and vibration of the working mechanism effectively.

The deflection and vibration along the vertical direction of the coal wall cross are very small compared with the deflection and vibration in other directions based on many field experiments. This difference is because the stiffness of the working mechanism along the drilling direction is significantly larger than that in other directions. This paper primarily focuses on researching the deflection and vibration characteristics of the coal auger working mechanism and present effective control measures for directional drilling, where the deflection and vibration along the drilling direction have little influence. Based on the above analysis, this paper does not focus much research on the deflection and vibration along the vertical direction.

\section{Experiment Study}

2.1. Experiment Method. The five-drill-bit coal auger working mechanism mainly consists of three rows of drill-rods, two rows of vent-tubes, a transmission box, and five drill-bits. Due to the space and condition limitations in the laboratory, the drilling experiment cannot reach the size and drilling depth as in an actual application. Therefore, drilling depth was set at one, two, three, and four drill-rod sections in the experiment. The drilling test bed of the working mechanism is shown in Figure 2.

The drilling test was conducted on artificial coal and rock, which was constructed based on the main mechanical properties of coal. Frequency conversion motor was used to drive the gear reducer to provide drilling torque for the working mechanism. Propulsion resistance was supplied by a hydraulic motor through a pinion-and-rack mechanism. Drilling torque, propulsion resistance, and deflection displacement were measured by GB-DTS200 digital torque sensor, JNBP-10 MPa pressure sensor, and HZ-891 electric eddy current displacement sensor, respectively. Hardness of the artificial coal and rock was $f=2.07$ and the rotation speed of the working mechanism was $n=60 \mathrm{r} / \mathrm{min}$.

2.2. Experiment Results. The displacements of the measuring points with different drill depths for one, two, three, and four drill-rod sections were obtained. Figure 3 shows the measuring points displacements of the auger with four drillrod sections. It shows that the displacements have changed 
TABLE 1: Statistics of deflection displacements of the working mechanism with four drill-rods.

\begin{tabular}{|c|c|c|c|c|c|c|c|}
\hline \multicolumn{2}{|c|}{ Statistical parameters } & $x$-left & $y$-left & $x$-middle & $y$-middle & $x$-right & $y$-right \\
\hline \multirow{3}{*}{ Measuring point 1} & Average & 0.37 & 0.21 & 0.56 & 0.74 & -0.31 & 1.01 \\
\hline & Standard deviation & -0.60 & 0.29 & -0.30 & -0.25 & 0.15 & 0.16 \\
\hline & Maximum & 3.36 & 0.44 & -0.06 & -0.80 & -1.29 & 0.38 \\
\hline \multirow{3}{*}{ Measuring point 2} & Average & -1.85 & 0.85 & 2.12 & -0.17 & -5.35 & -0.69 \\
\hline & Standard deviation & -2.46 & 0.36 & -1.48 & -0.30 & -5.61 & -2.32 \\
\hline & Maximum & 5.22 & 1.67 & 3.91 & 1.17 & -2.47 & 5.93 \\
\hline \multirow{3}{*}{ Measuring point 3} & Average & 2.63 & -0.80 & -0.74 & -0.84 & -1.13 & -2.95 \\
\hline & Standard deviation & 0.00 & -0.58 & 0.61 & -0.10 & -0.10 & 1.1 \\
\hline & Maximum & 7.23 & 2.12 & 3.33 & 2.47 & 2.64 & 11.54 \\
\hline \multirow{3}{*}{ Measuring point 4} & Average & 1.46 & -0.90 & 0.70 & -1.14 & -1.32 & -3.41 \\
\hline & Standard deviation & 0.16 & -0.08 & 0.29 & -0.02 & -0.17 & -0.46 \\
\hline & Maximum & 12.48 & 4.12 & 4.68 & 2.87 & 3.15 & 8.53 \\
\hline
\end{tabular}

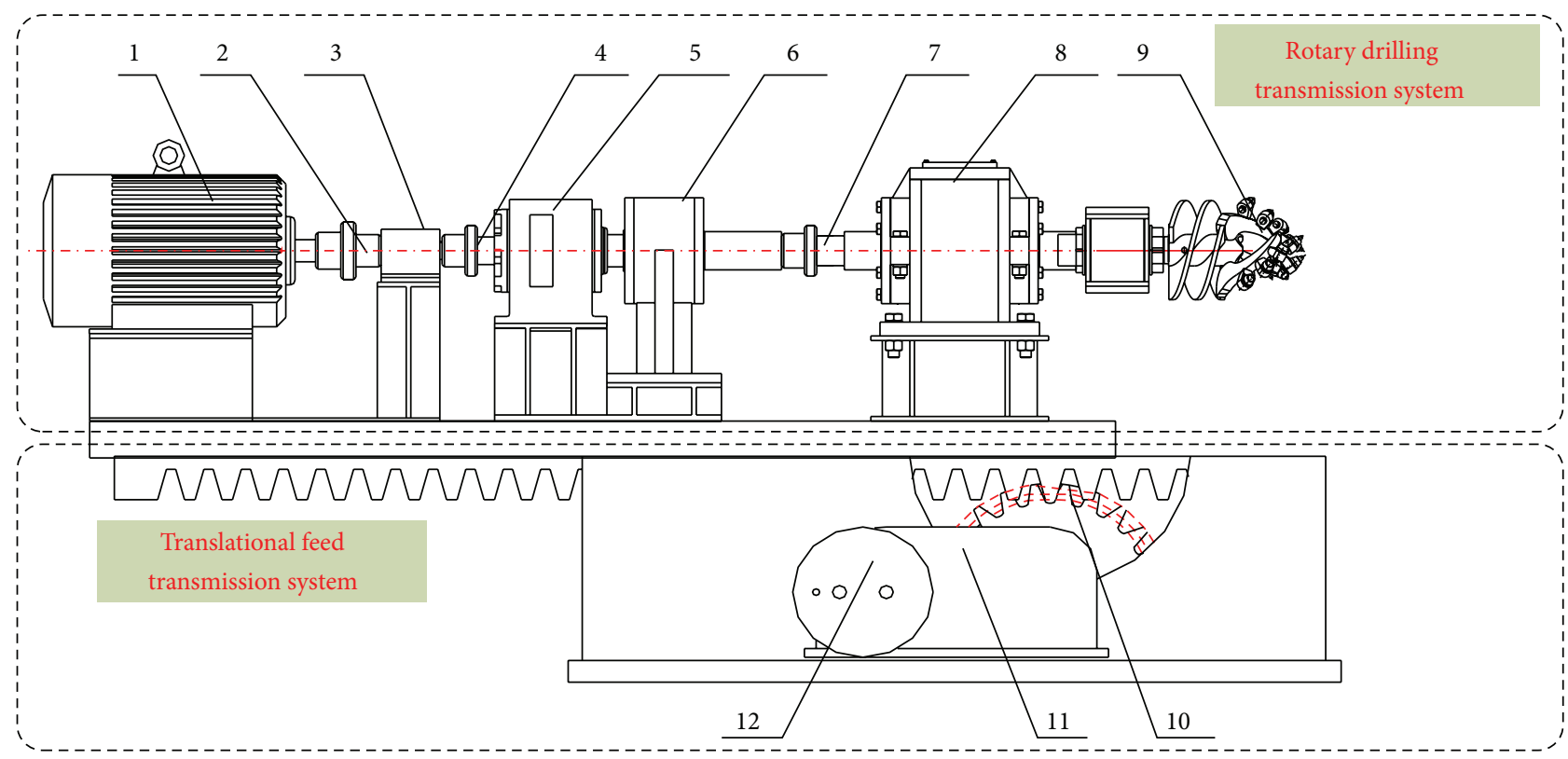

Rotary drilling transmission system
(1) Motor
(2) Coupling 1
(3) Torque sensor
(4) Coupling 2
(5) Gear reducer 1
(6) Bearing support
(7) Coupling 3
(8) Transmission case
(9) Drill-bit

Translational feed transmission system

(10) Rack-and-pinion mechanism

(11) Gear reducer 2

(12) Hydraulic motor

FIGURE 2: Drilling test bed of the working mechanism.

significantly when the drill-bit drills into the coal seam after $t=5 \mathrm{~s}$. The statistics of deflection displacements at each measuring point are shown in Table 1, and the statistic laws are shown in Figure 4.

As shown in Figure 4, the working mechanism deflects to the right side slightly in the $x$ direction and both the maximum deflection and vibration occur in the middle of the working mechanism. In the $y$ direction, the drill-rod slants downwards, whereas the drill-bit tilts slightly upwards. The deflection of the drill-rod close to the drill-bit is larger, and the maximum vibration also appears in the middle of the working mechanism. 

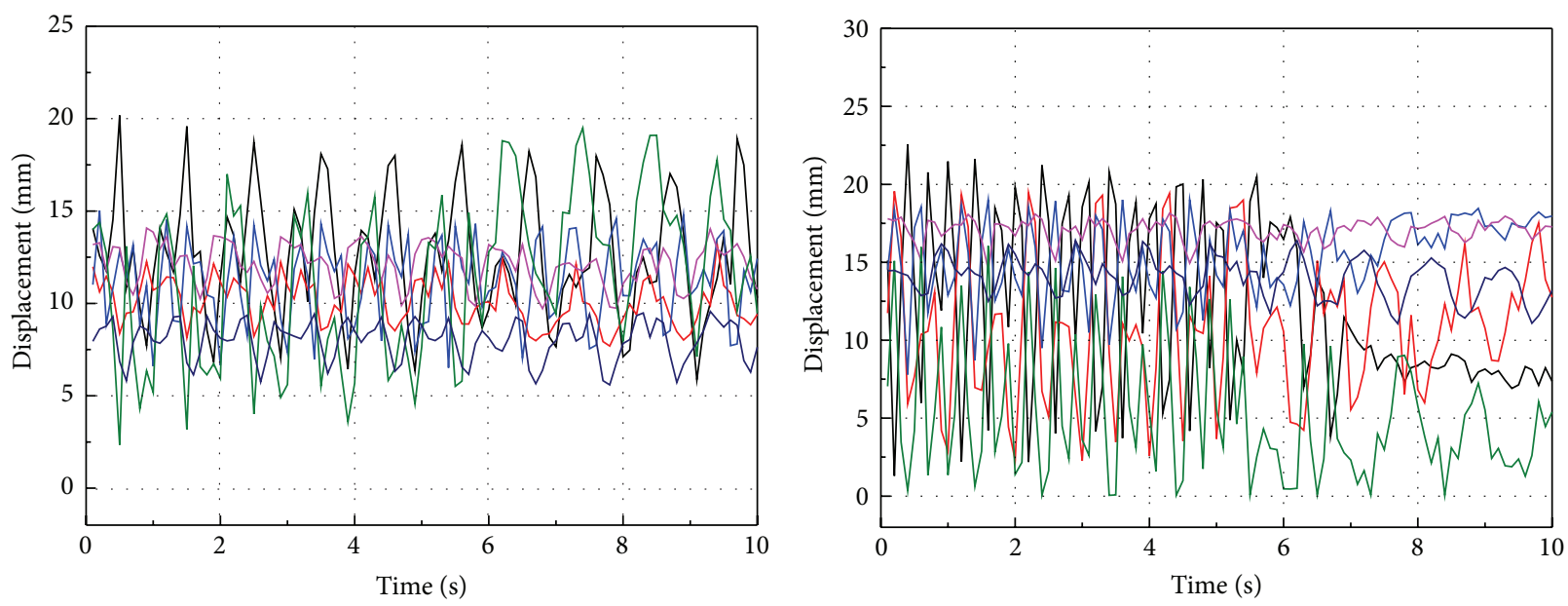

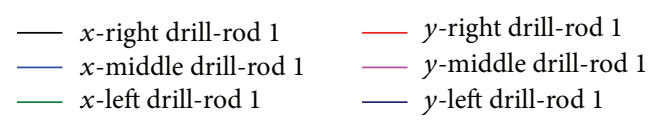

(a) Displacement of measuring point 1
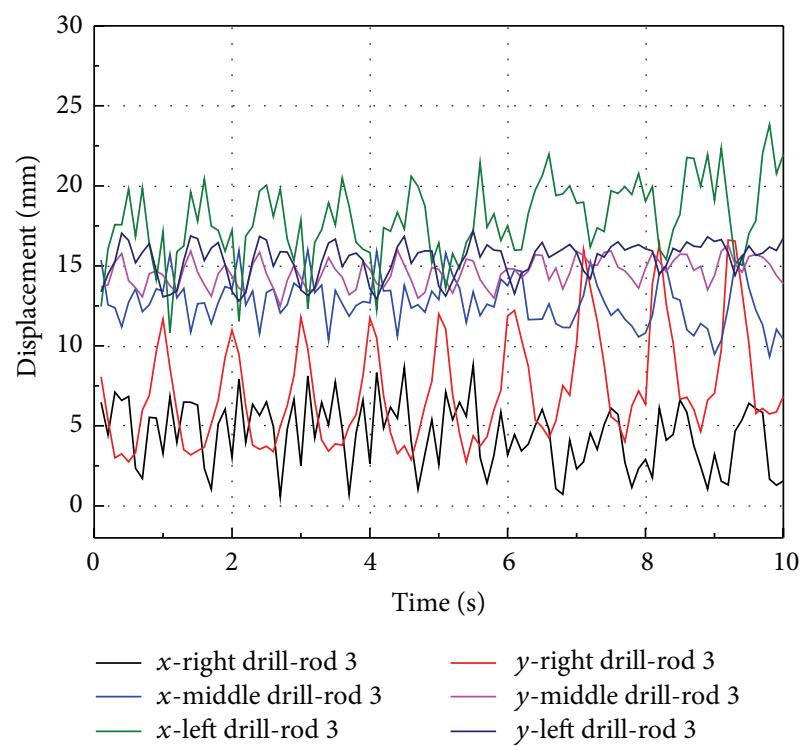

(c) Displacement of measuring point 3

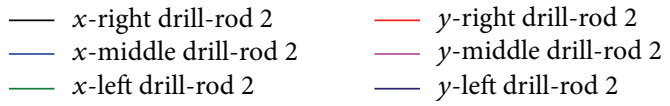

(b) Displacement of measuring point 2
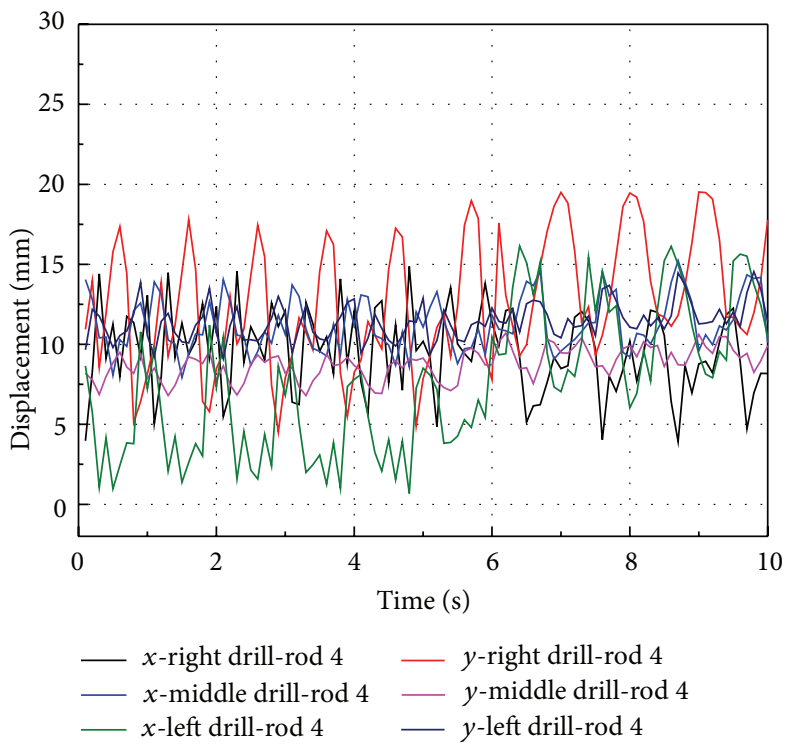

(d) Displacement of measuring point 4

FIGURE 3: Experiment results of a working mechanism with four drill-rods.

To illustrate the relationship between deflection and different drilling depths, the test load data statistics at the drillrod are conducted. The average and maximum displacement curves are obtained as shown in Figure 5. Figure 5 shows that the deflection displacement of the working mechanism increases with the drilling depth in the $x$ direction but increases first and then becomes stable in the $y$ direction.

The drilling depth increases with the drill-rod and venttube section by section in the process of drilling which leads the overall stiffness of the working mechanism to decrease continuously. In the $x$ direction, the left and right drillrods deflect to the opposite direction under the effect of the friction force by the coal wall hole. The effect of the friction force increases with the drilling depth, leading to the drillrod deviation increase obviously as well as the drill-rod vibration. The maximum vibration occurred in the central position of the drill-rods. In the $y$ direction, the central position of the drill-rods gradually closed on to coal wall hole with an increase in the drilling depth under the combined action of the drill-rod weight and hole constraints. As the drilling depth reached a certain value, the number of drillrods that made contact with the coal wall hole gradually increased due to gravity, which tends to make the whole working mechanism stable. The vibration of drill-rods in the $y$ direction increases with the drilling depth at first because of the collision between the drill-rods and the coal wall hole 
TABLE 2: Deflection displacement statistics under different drilling depths.

\begin{tabular}{|c|c|c|c|c|c|c|}
\hline \multirow{2}{*}{ Drilling depth } & \multicolumn{3}{|c|}{ Propulsion resistance/kN } & \multicolumn{3}{|c|}{ Drilling torque $/ \mathrm{N} \cdot \mathrm{m}$} \\
\hline & Average & Standard deviation & Maximum & Average & Standard deviation & Maximum \\
\hline Drill-rod 1 & 24.51 & 0.57 & 27.48 & 222.20 & 17.02 & 278.91 \\
\hline Drill-rod 2 & 25.45 & 0.54 & 27.88 & 240.66 & 17.45 & 288.40 \\
\hline Drill-rod 3 & 25.85 & 0.54 & 28.79 & 270.84 & 17.83 & 334.25 \\
\hline Drill-rod 4 & 26.41 & 0.50 & 29.40 & 297.13 & 18.21 & 334.42 \\
\hline
\end{tabular}

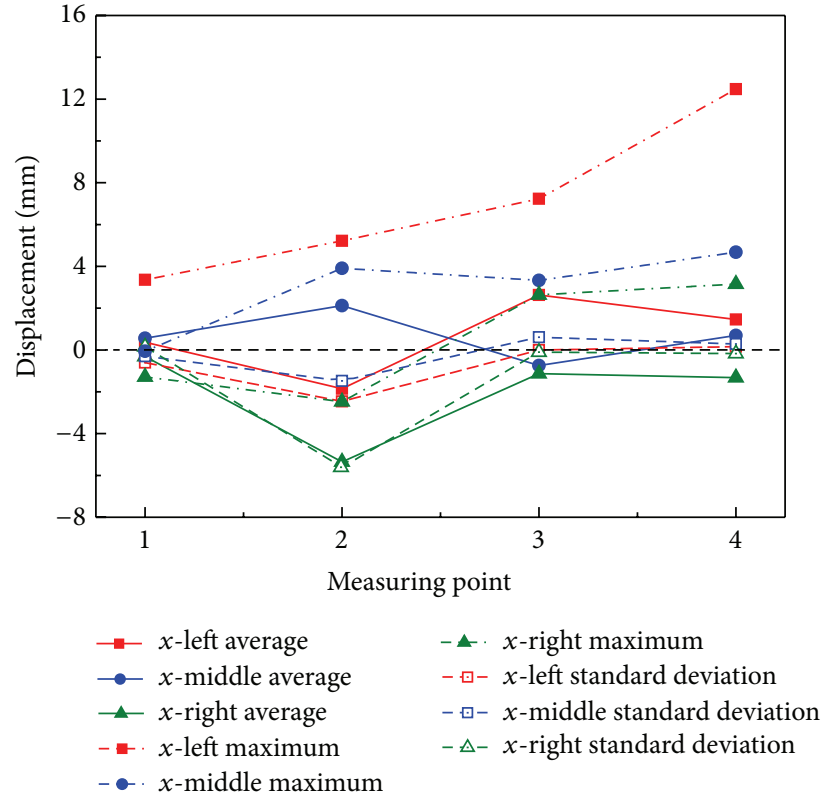

(a)

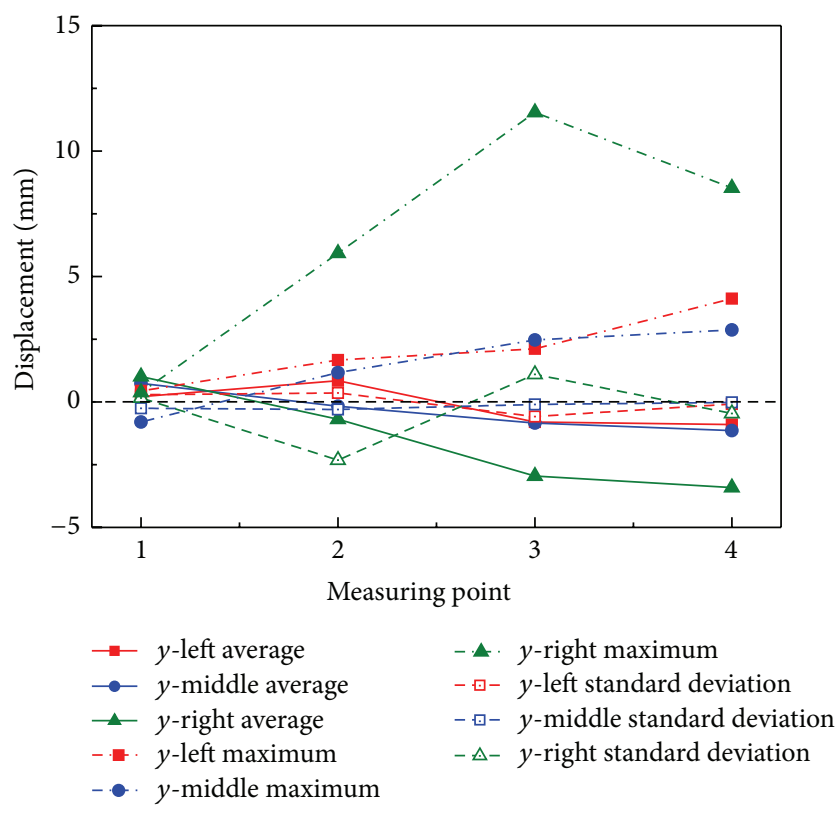

(b)

FIGURE 4: Deflection displacement statistic law of the working mechanism with four drill-rods.

and the maximum vibration occurs in the middle of the whole drill-rods. Finally, the vibration reaches a balance as well as the deflection.

Table 2 shows the statistics of propulsion resistance and drilling torque of the working mechanism under different drilling depths. Influence of drilling depth on the propulsion resistance and drilling torque was obtained from Table 2, shown in Figure 6. It can be seen from Table 2 and Figure 6 that the propulsion resistance and drilling torque of the working mechanism increase with an increase in the drilling depth. In contrast, little fluctuation of propulsion resistance and drilling torque was changed during the process.

\section{Simulation Model Establishment}

The vibration and deflection of the working mechanism are affected by many different factors that cannot be investigated by the overall test. Therefore, a simulation was put forward for further studies.

3.1. Basic Hypotheses. The coal auger working mechanism is mainly composed of the drill-bit, segmented drill-rod, and vent-tube, which is pushed forward by adding the segmented drill-rod and vent-tube. With increasing drilling depths, the axial size of the working mechanism increases at a far greater rate than its radial size. At the same time, affected by gravity, drilling load, friction, and collision force between the working mechanism and the coal wall, the working mechanism is prone to violent vibrations and serious deflections in the drilling process. To study the vibration and deflection behavior of the working mechanism, the following hypotheses were put forward:

(1) The cross section of the coal wall hole is a circle, and the drilling direction is horizontal.

(2) The drill-bit is set as a rigid body, and the drill-rod is an elastomer. Initially, drill-rod is coincident with the horizontal axis of the coal wall.

(3) The contact and collision between the drill-rod and coal wall occur randomly because the drill-rod is constrained by the bore wall.

(4) The frictional resistance between coal particles and drill-rod during transportation is ignored.

(5) The vibration and deflection of the working mechanism are divided into $x$ and $y$ components (the $x$ component is the horizontal direction of the coal wall 


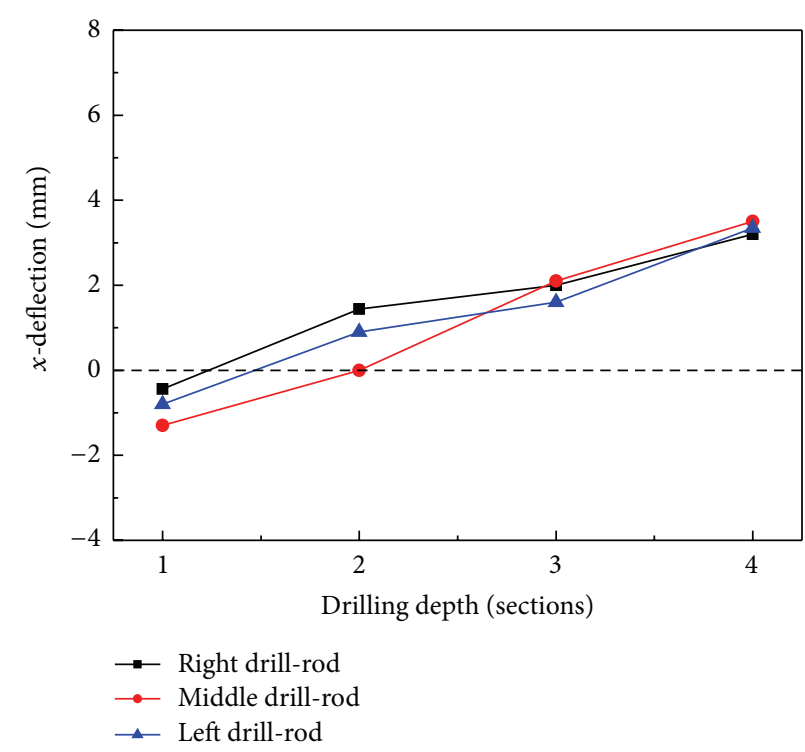

(a)

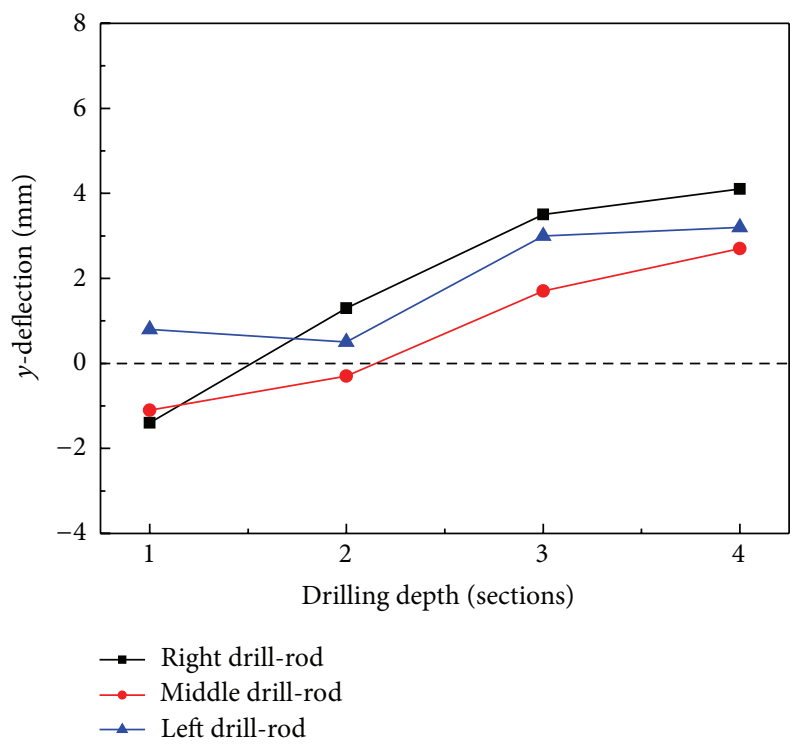

(c)

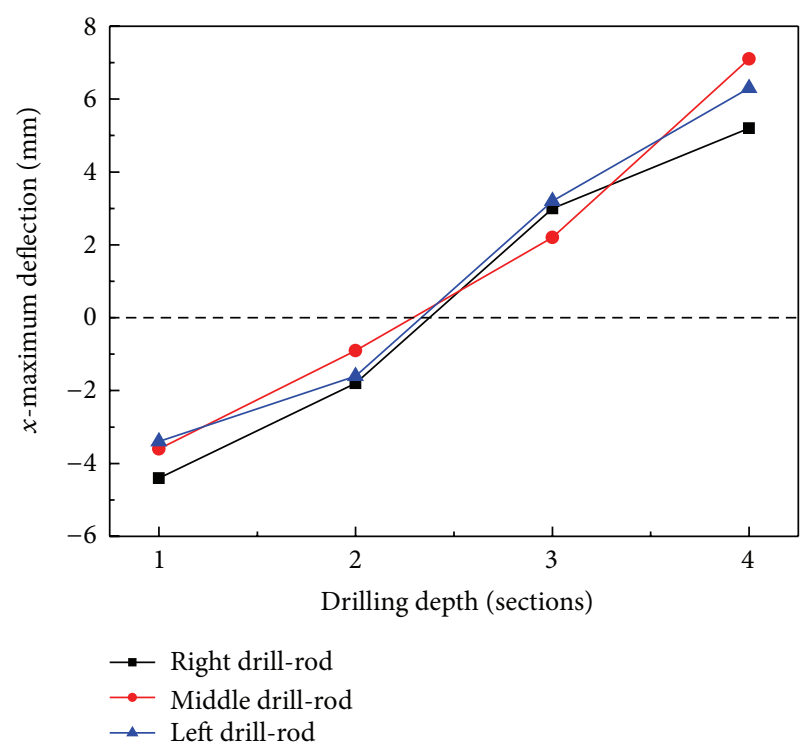

(b)

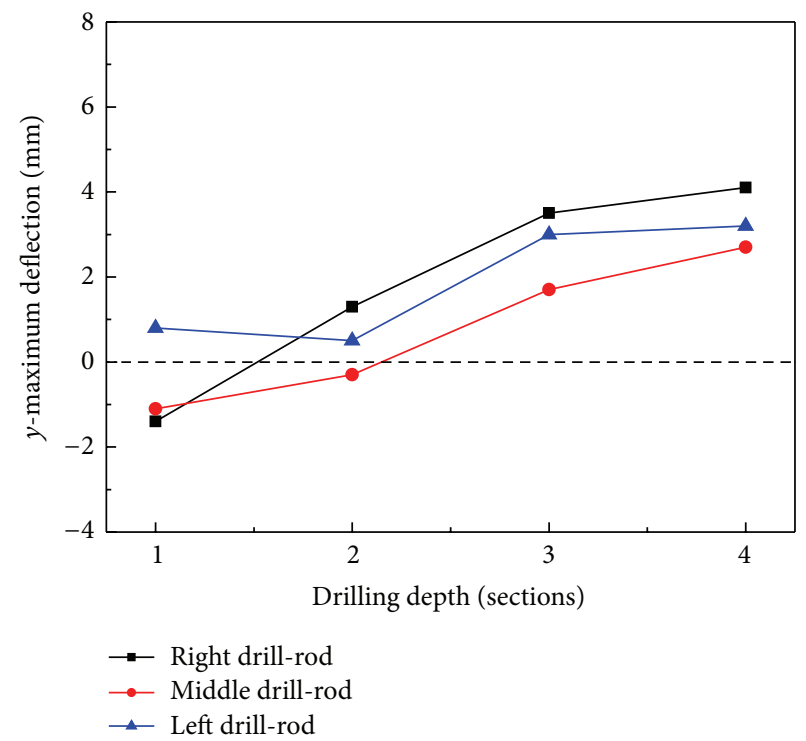

(d)

FIGURE 5: Deflection statistical law of the working mechanism under different drilling depths.

cross section, and the $y$ component is the vertical direction).

3.2. Simulation Model. Based on the above hypotheses, a three-dimensional entity model of the working mechanism was established and imported into software ADAMS. Simulation model was obtained after quality property definition, drill-rod flexibility, constraints addition, contacts addition, drives, and loads addition. Virtual prototype of five-bit coal auger working mechanism is shown in Figure 7.

The vibration and deflection behavior of the five-bit coal auger working mechanism were analyzed in the context of the drilling depth, partial load form, and stabilizer arrangement according to the actual usage in the underground coalmine. The drilling depths were set at $8.3 \mathrm{~m}, 10.7 \mathrm{~m}, 13.1 \mathrm{~m}$, and $17.1 \mathrm{~m}$. Partial load for single bit (A), two bits (A and C), and three bits (A, C, and E) was subjected to complex coal seam load, shown in Figure 8. Simple coal seam hardness in the simulation model is $f=2.07$, and complex coal seam hardness is $f=3.6$. The corresponding torque and propulsion force were obtained from cutting simulation, as shown in Figure 6. Stabilizer was arranged every three, four, five, and six drill-rods. In addition, propulsion speed of the working mechanism is $1 \mathrm{~m} / \mathrm{min}$ and the rotation speed is $60 \mathrm{r} / \mathrm{min}$. 

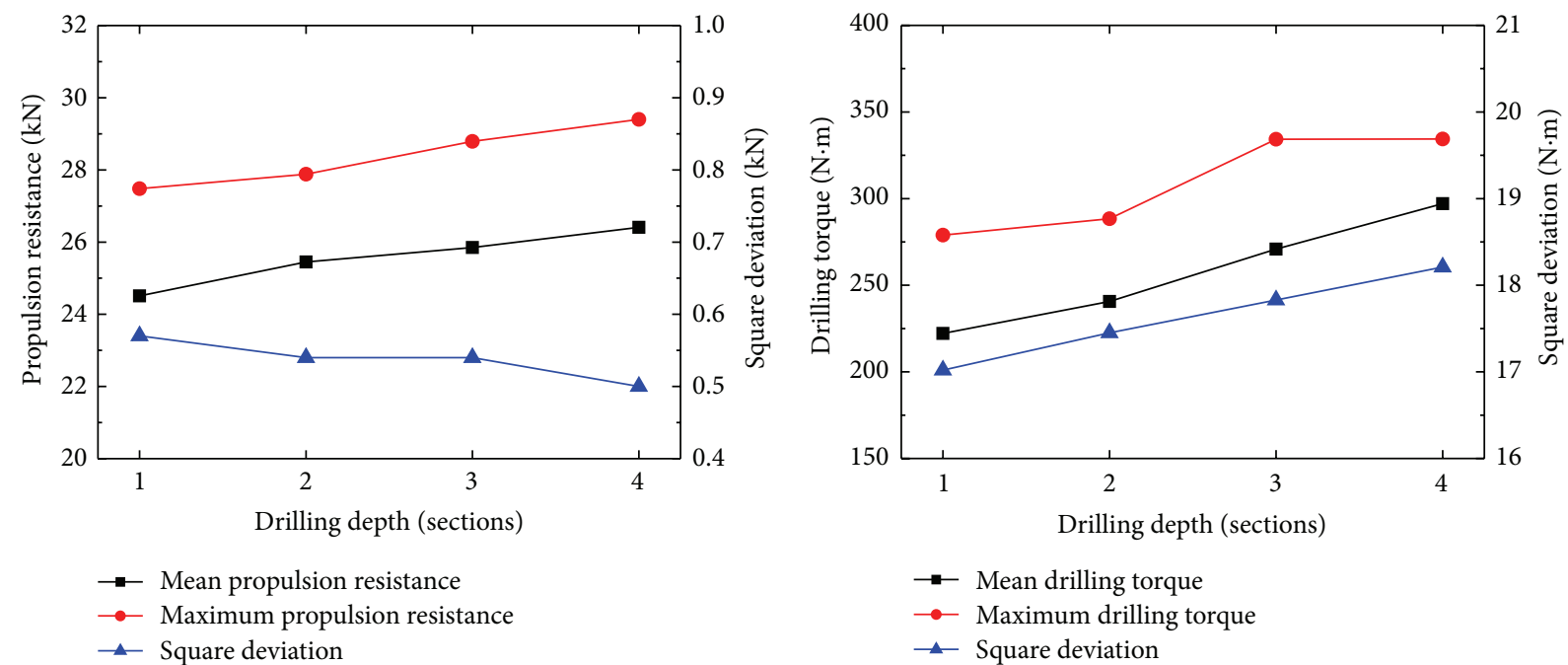

FIGURE 6: Relationship between propulsion resistance and drilling torque of the working mechanism and drilling depth.

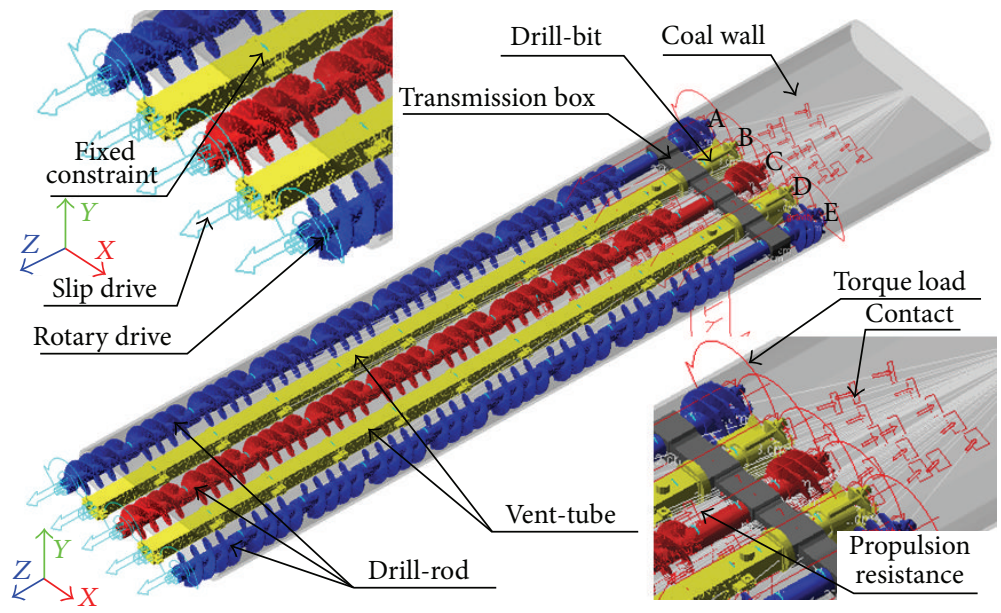

FIGURE 7: Rigid-flexible coupling simulation model of the working mechanism.
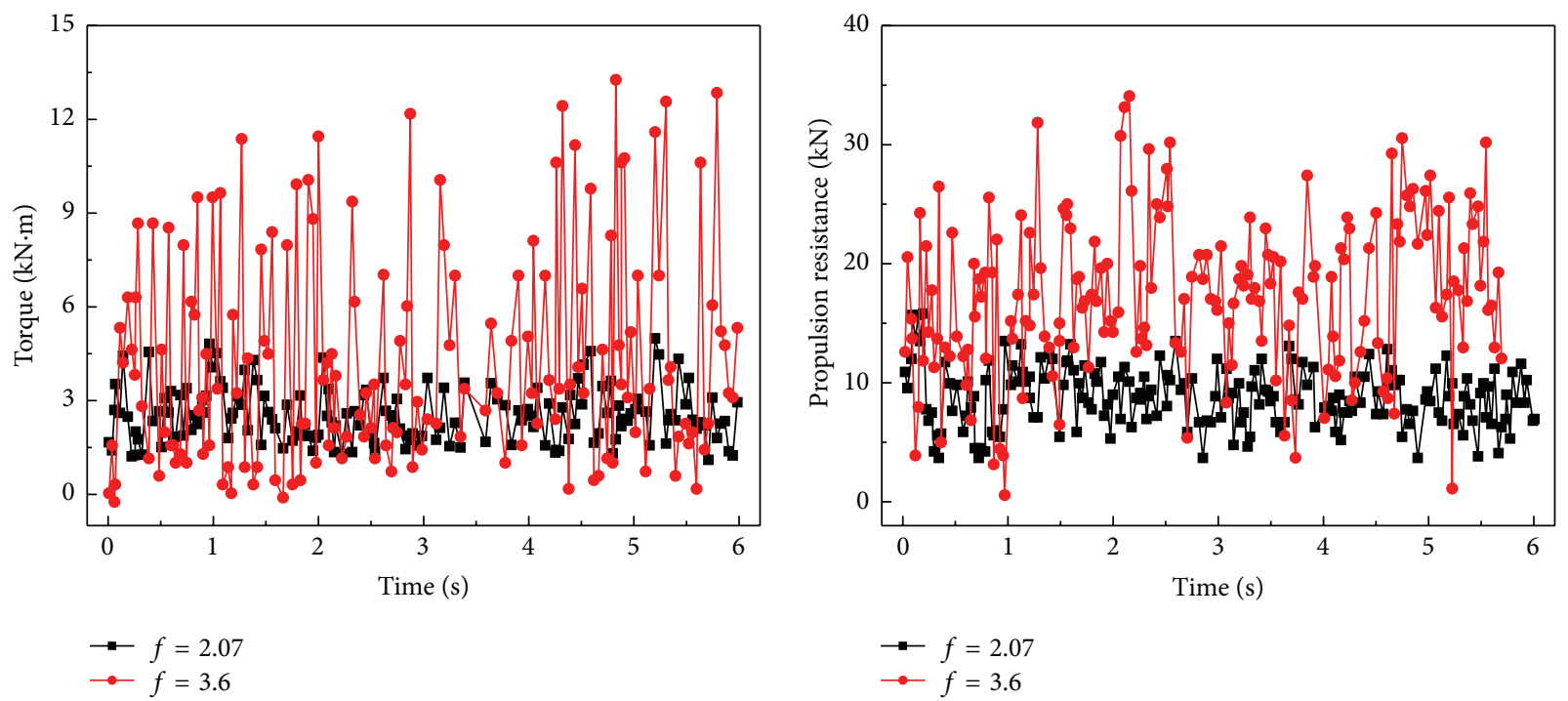

FIgURE 8: Torque and propulsion loads in simple and complex coal seam. 


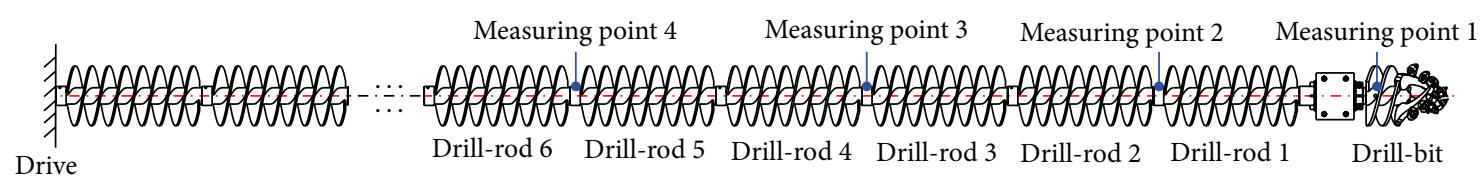

FIGURE 9: Arrangement of measuring points.
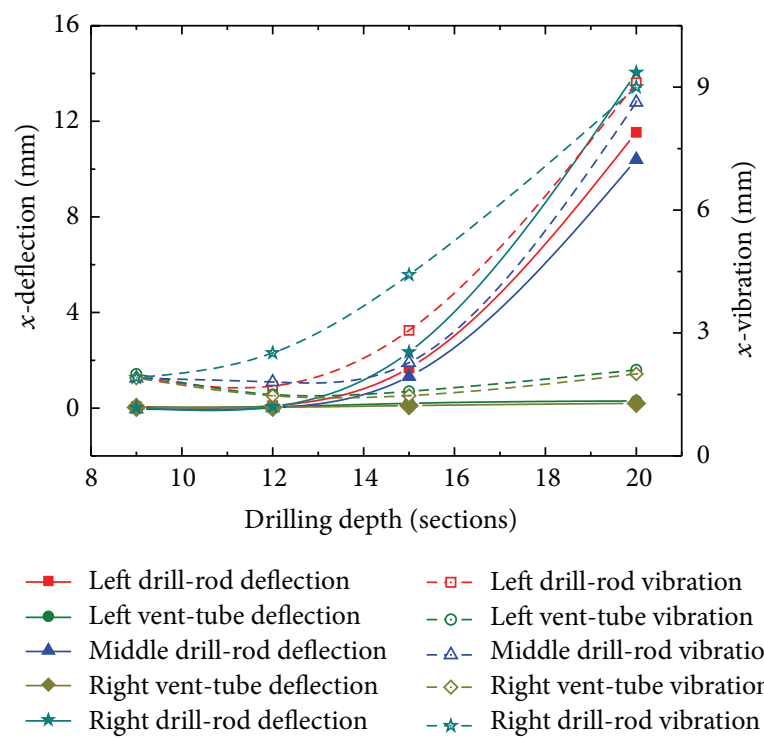

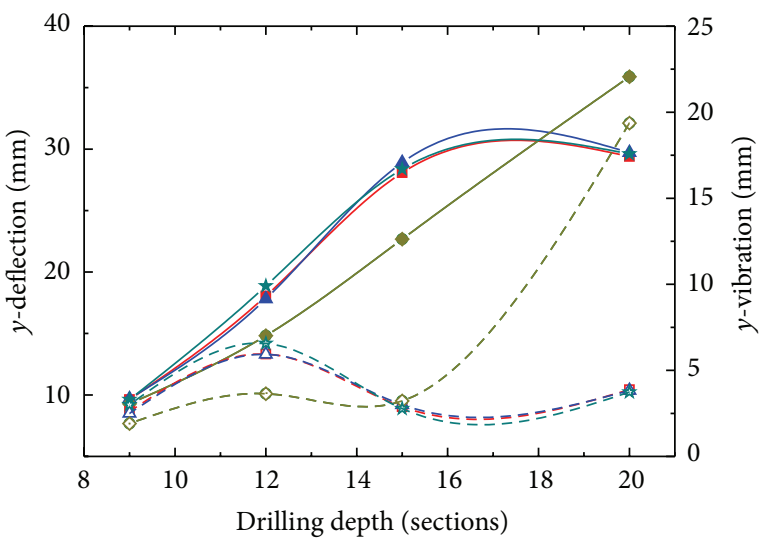

- Left drill-rod deflection

$\rightarrow$ Left vent-tube deflection

- Middle drill-rod deflection

$\smile$ Right vent-tube deflection

* Right drill-rod deflection

$$
\begin{aligned}
& -\bullet-\text { Left drill-rod vibration } \\
& -\odot-\text { Left vent-tube vibration } \\
& -\diamond-\text { Middle drill-rod vibration } \\
& -\diamond-\text { Right vent-tube vibration } \\
& -\downarrow-\text { Right drill-rod vibration }
\end{aligned}
$$

FIGURE 10: Relationship between vibration and deflection of working mechanism and drilling depth.

\section{Simulation Results}

Figure 9 shows the arrangement of different measuring points in the simulation. From displacement and force statistical analyses at different measuring points, the vibration, deflection, and collision force can be obtained.

4.1. Influence of Different Drilling Depths. Figure 10 shows the relationship between drilling depth, vibration, and deflection behaviors of the working mechanism. It can be seen from Figure 10 that the deflection and vibration of the left, middle, and right drill-rods in the $x$ direction increase with an increase in the drilling depth, but left and right vent-tubes show no significant change. With an increase in the drilling depth, the deflection of drill-rods along the $y$ direction gradually increases and tends to be steady when the drilling depth reaches 15 drill-rod sections. However, the vibration of the drill-rods in the $y$ direction reaches the maximum at a drilling depth of 12 drill-rod sections and gradually tends to be stable as the drilling depth further increases. Because spacing between the vent-tube and the coal wall is greater than that of the drill-rod and coal wall, the deflection and vibration of the left and right vent-tubes gradually increase with an increase in the drilling depth in the $y$ direction. According to the deflection and vibration characteristics of the left and right drill-rods, it is speculated that the deflection and vibration of the left and right vent-tubes will also gradually tend to be a stable value after reaching a certain drilling depth. Compared with Figure 5, the experimental results coincide with the simulation results and then verify the correctness of the simulation.

While the drilling depth is $10.7 \mathrm{~m}$ (12-section drill-rod), the time-displacement curves of the different measuring points in the $x$ and $y$ directions are shown in Figures 11 and 12, respectively. It can be seen that the vibration of the working mechanism is larger in its infancy and gradually tends to be more stable with time; the vibration and deflection at the middle drill-rod are larger but relatively small at both ends; the vibration and deflection of the drill-rod and the venttube are greatly different from each other in the $x$ and $y$ direction at the same measure point. The drill-rod vibration is considerably larger than the vent-tube and consistent at measuring point 1 because of the fix of transmission box.

The contact force that was generated by the collision between the coal wall and each row of the drill-rods of the working mechanism and vent-tubes is shown in Figure 13. We can see that the collision mainly occurs at the left and right drill-rods on both sides and the collision force orientation is opposite in the $x$ direction and the same in the $y$ direction. Comparing Figures 13(a) and 13(b), the collision force of onesided drill-rod of working mechanism in the $y$ direction is five times as great as that in the $x$ direction.

Figure 14 shows the changing trends of the collision force with drilling depth. It is observed that the collision force of working mechanism in both the $x$ and $y$ directions tends to increase nearly linearly, along with the mean square error. This suggests that the overall force of working mechanism increases after drilling into the coal seam, which results in 

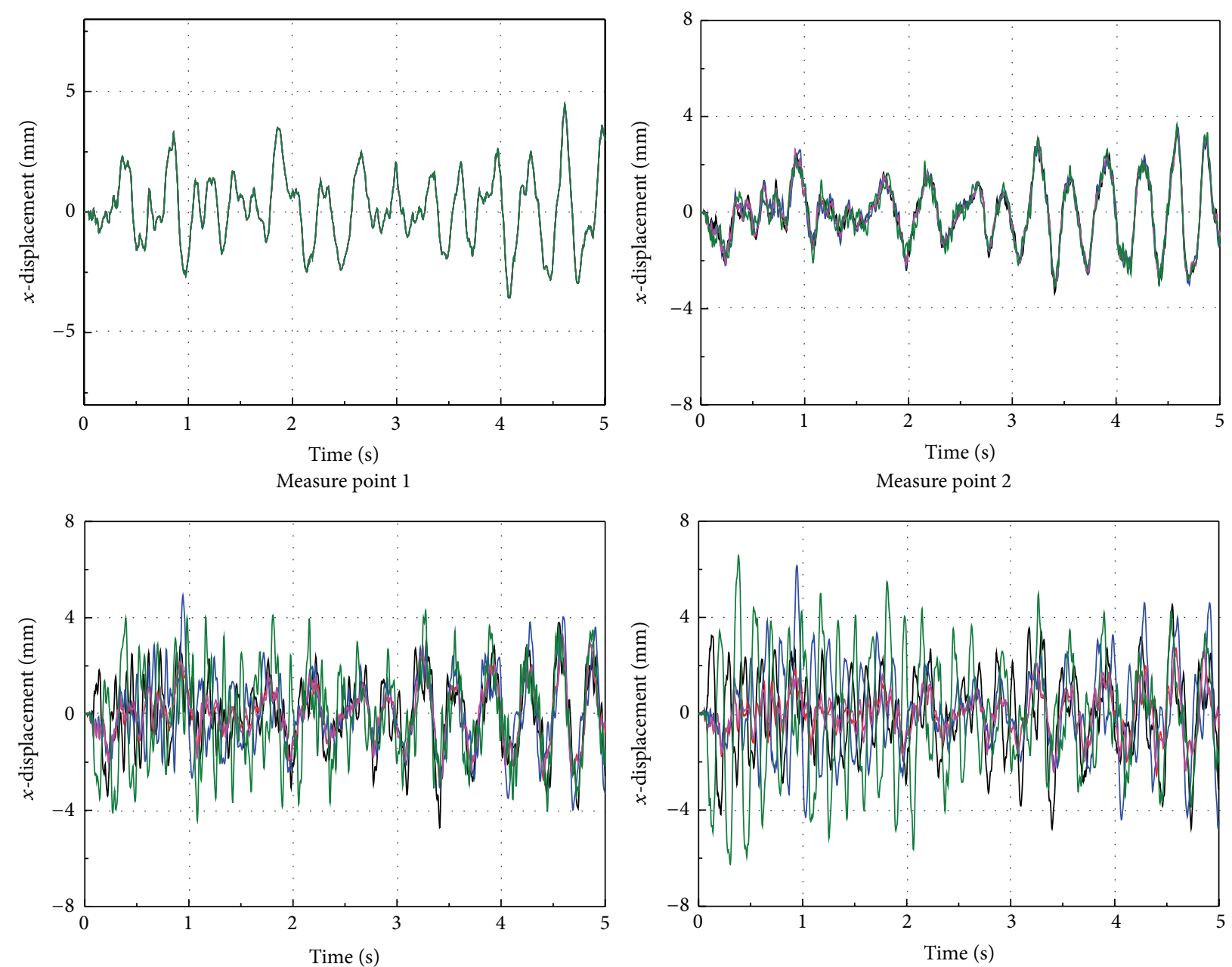

Measure point 3

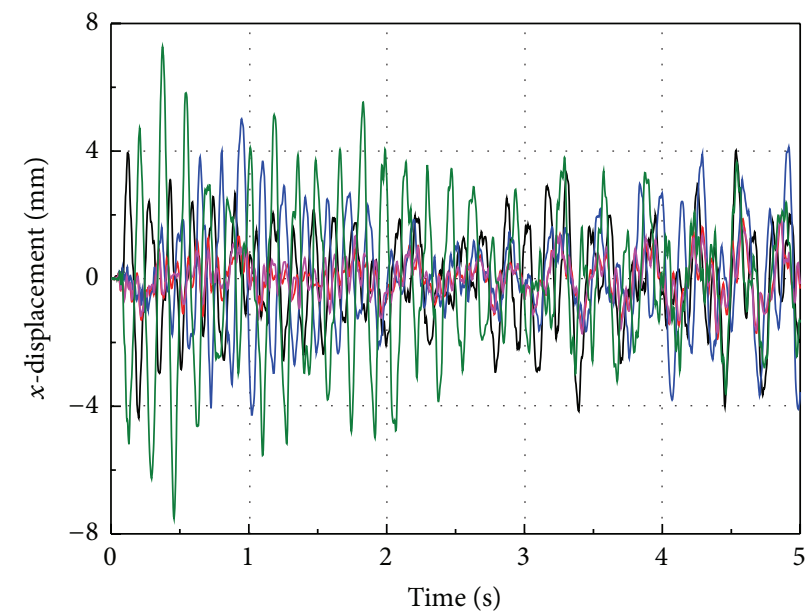

Measure point 4

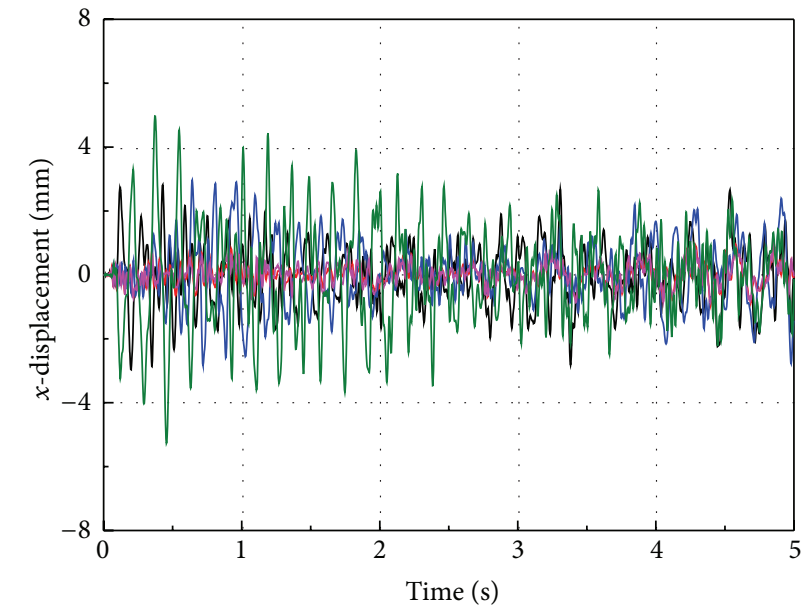

Measure point 5

Measure point 6

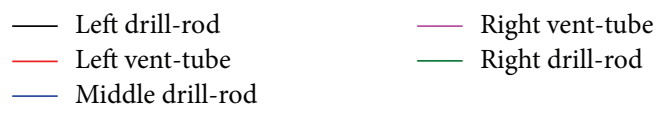

$\begin{array}{ll}\text { —_ } & \text { Left drill-rod } \\ \text { — } & \text { Left vent-tube } \\ \text { - Middle drill-rod }\end{array}$

- Right vent-tube

— Right drill-rod

FIGURE 11: Displacement curves of working mechanism in $x$ direction with a drilling depth of $10.7 \mathrm{~m}$. 

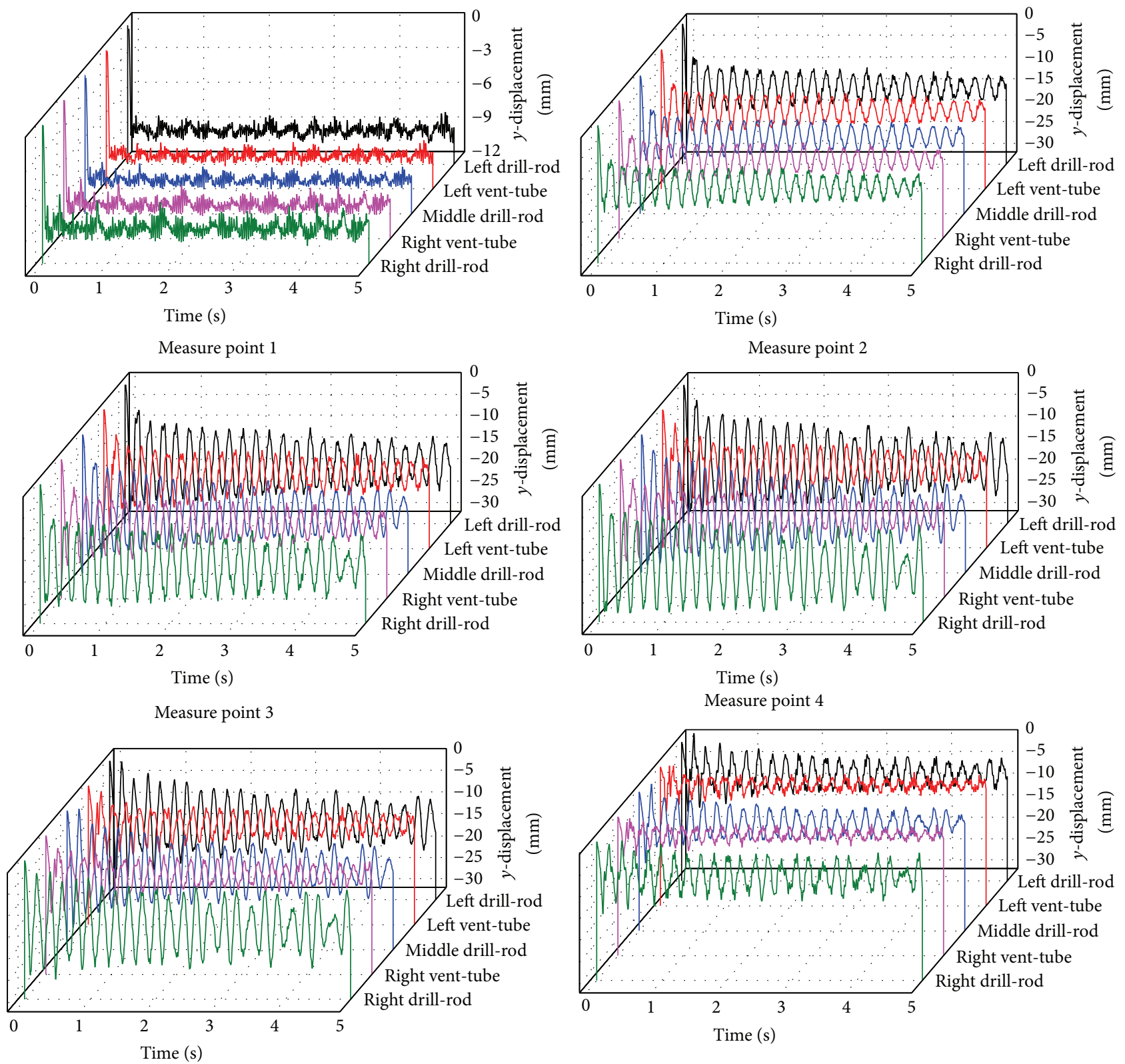

Measure point 5

Measure point 6

FIGURE 12: Displacement curves of working mechanism in $y$ direction with a drilling depth of $10.7 \mathrm{~m}$.

the aggravation of the deflection and vibration degree and the approximately linear relationship with the drilling depth.

\subsection{Influence on Different Partial Load Modes. Large mining} width of the working mechanism during the drilling process would cause a partial load. For a different working condition, the partial load form is different. Hence, a simulation of the vibration and deflection behavior under the following different partial load forms was carried out: (I) nonpartial load; (II) only drill-bit A bearing a complex coal seam load; (III) both drill-bits A and C bearing a complex coal seam load; and (IV) drill-bits A, C, and E bearing a complex coal seam load simultaneously, as shown in Figures 15-18.
Comparing Figures 16(a), 17(a), and 18(a) shows that the working mechanism overall deflects to the right side when only the drill-bit A bears the partial load, and the maximum deflection position is near the fourth to fifth drillrod sections. When the drill-bits $\mathrm{A}$ and $\mathrm{C}$ simultaneously bear partial load, working mechanism would deflect to the right side, but the magnitudes of the deflection and vibration are both less than the magnitude when only the drill-bit A bears the partial load. When the left, middle, and right three drill-bits simultaneously bear complicated seam load, various drill-rods will have a slight deflection deformation which is consistent with their own rotation direction, but the working mechanism overall drills along the straight direction. 


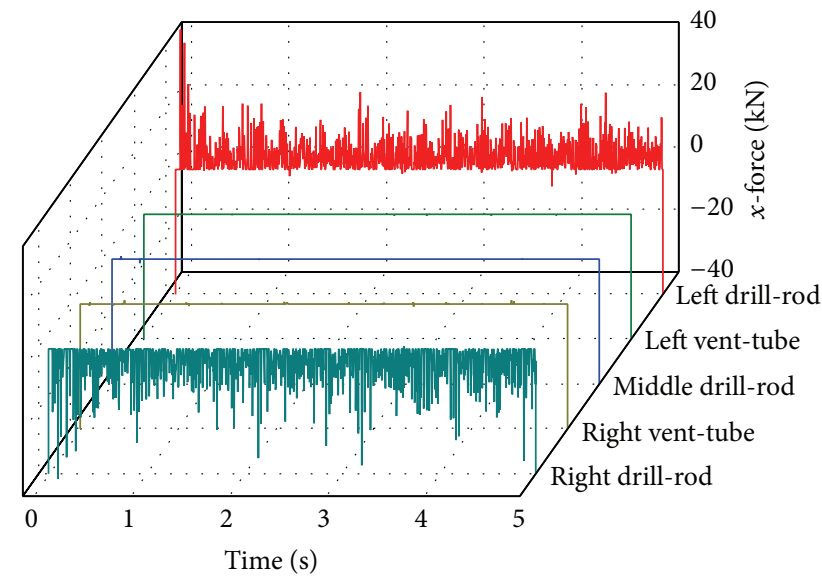

(a)

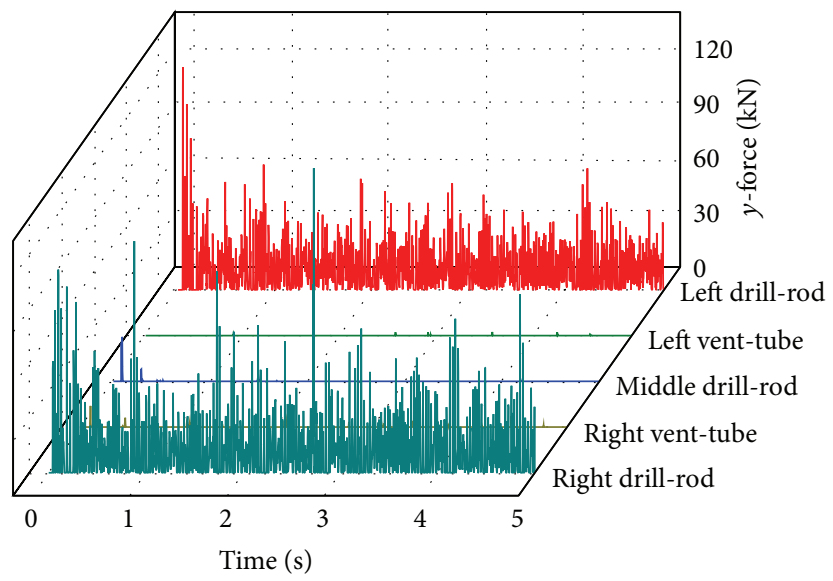

(b)

FIGURE 13: Collision force in $x$ and $y$ directions with a drilling depth of $10.7 \mathrm{~m}$.

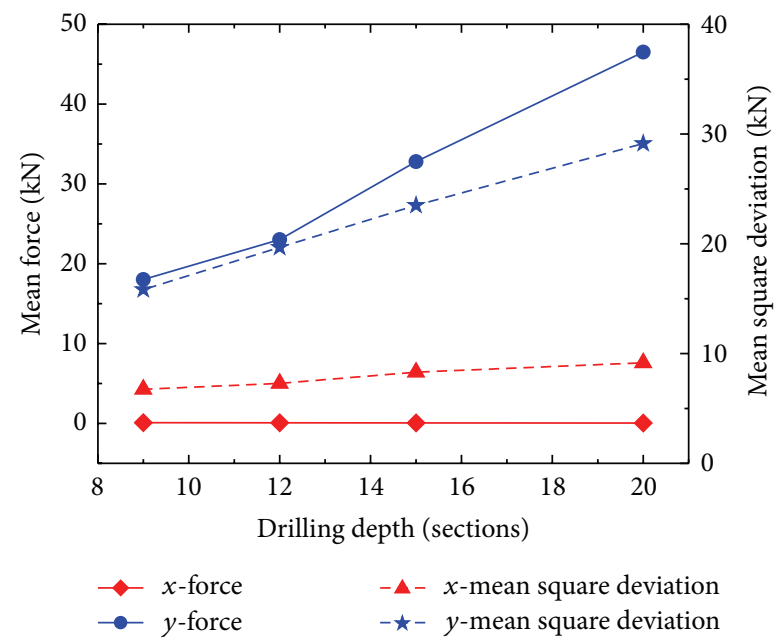

FIGURE 14: Relationship between working mechanism collision force and drilling depth.

Comparing Figure 15(a) with Figure 18(a), the deflection and the vibration of work mechanism are basically similar under different load forms, but the amplitudes under a complex coal seam load are greater than nonpartial load. The above analysis shows that the working mechanism would deflect to the opposite side under a unilateral partial load, while remaining unchanged basically under an equalizing load. The amplitude changes are a positive correlation with the size of the partial load.

It can be seen from Figures 16(b), 17(b), and 18(b) that the deflection mode of the working mechanism has a little change in the $y$ direction; the maximum deflection location is near fifth drill-rod. Meanwhile, the vibration range of the working mechanism reduces with a decrease in the partial load, which is more stable under a relatively balanced drilling load. Considering Figure 15(b), the total load of the working mechanism gradually increases under the four proposed partial load conditions as well as the deflection and the relative deflection between each row of drilling tools.

4.3. Influence of Different Stabilizer Arrangements. Drillrod stabilizer is used to control and weaken the deflection and vibration of the working mechanism for long distance drilling, whose arrangements have an important influence on the drilling efficiency. To arrange the stabilizer more intuitively and effectively and find the relationship with deflection and vibration, different stabilizer arrangements were researched as shown in Figures 19 and 20. The stabilizer was arranged along the working mechanism, every six, five, four, and three drill-rod section intervals, in four ways. Meanwhile, the arrangement 0 represents the drilling process without a stabilizer placement.

As seen from Figure 19, the maximum deflection and vibration in the $x$ and $y$ directions gradually decrease with 

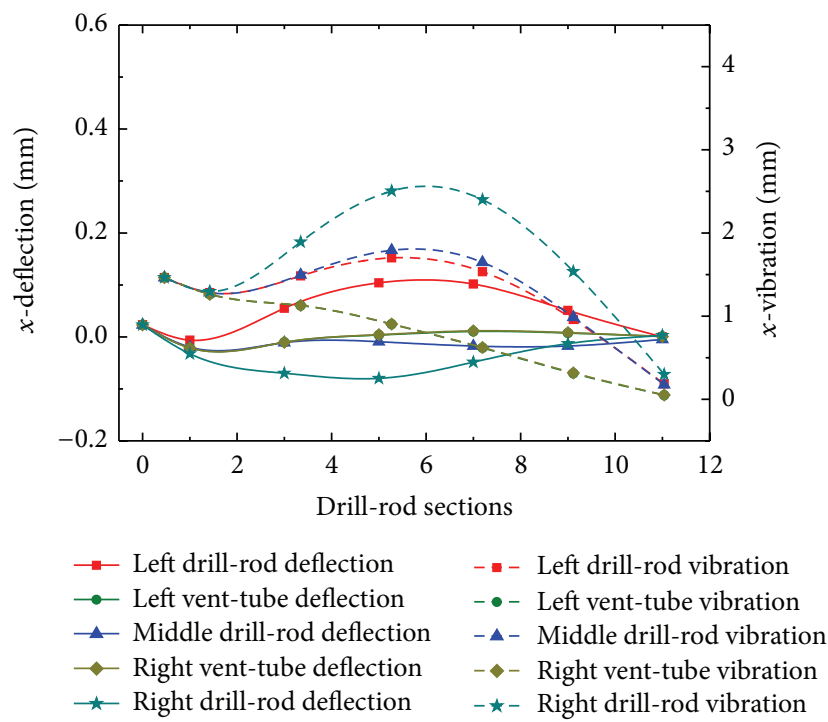

(a)

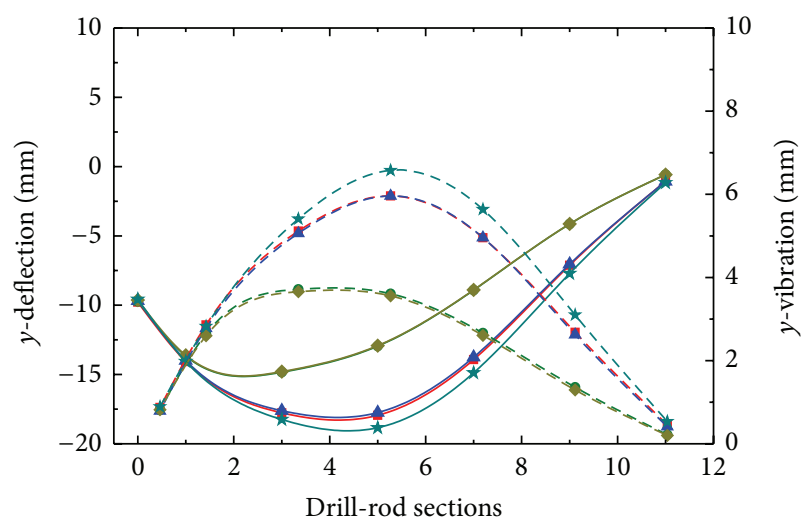

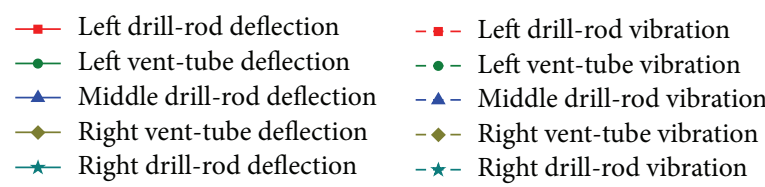

(b)

FIGURE 15: Vibration and deflection of the working mechanism without partial load.

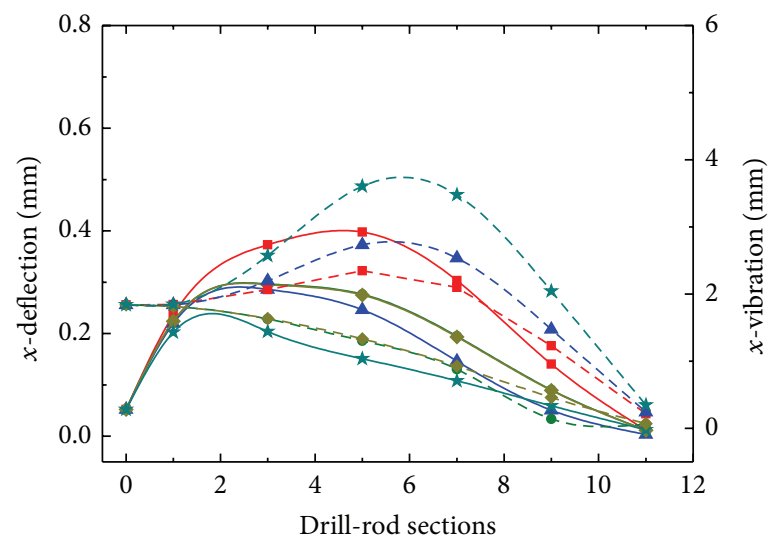

$\begin{array}{ll}\rightarrow \text { Left drill-rod deflection } & -\star-\text { Left drill-rod vibration } \\ \rightarrow-\text { Left vent-tube deflection } & -\bullet-\text { Left vent-tube vibration } \\ -\backsim \text { Middle drill-rod deflection } & -\star-\text { Middle drill-rod vibration } \\ \rightarrow-\text { Right vent-tube deflection } & -\star-\text { Right vent-tube vibration } \\ \star \text { - Right drill-rod deflection } & -\star-\text { Right drill-rod vibration }\end{array}$

(a)

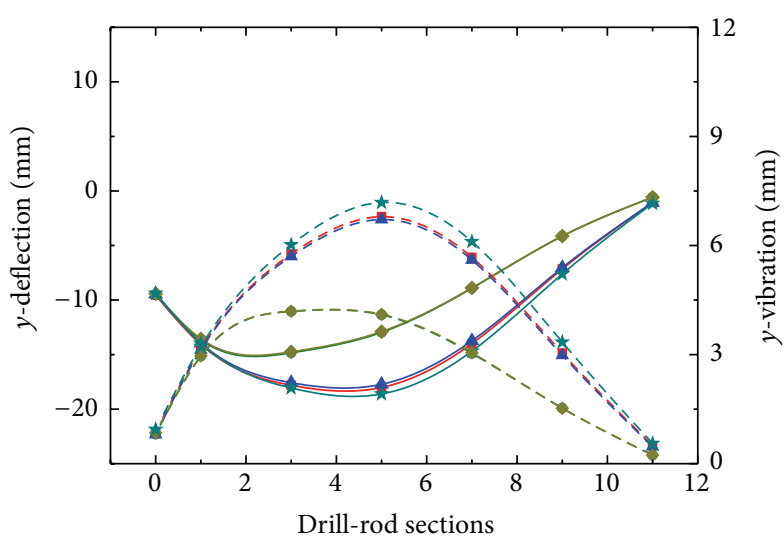

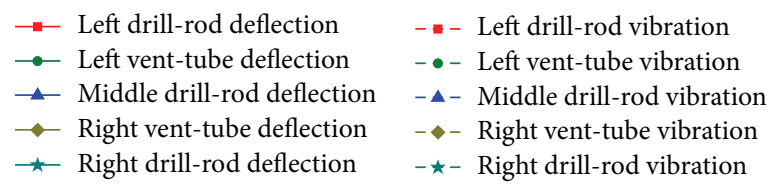

(b)

FIGURE 16: Vibration and deflection of the working mechanism (bit A subjected complex load).

the order number of stabilizer. After the stabilizer is arranged every five drill-rod section intervals, the increase in the order number of stabilizer has less influence on the maximum deflection and vibration in the $y$ direction. From this, it can be concluded that the stabilizer arrangement modes 2,3 , and 4 can effectively control the deflection and vibration.

Figure 20 shows that the mean deflection force of the working mechanism would appear positive and have negative alternation with the number of stabilizers increasing in the $x$ direction. However, the mean deflection force in the $y$ direction increases gradually with the number of stabilizers because the stabilizer arrangement directly affects the overall weight of the working mechanism. Meanwhile, the mean square error of the deflection force in the $x$ and $y$ directions gradually decreases with the number of stabilizers and reaches a minimum value under arrangement mode 2 . This concluded that stabilizer arrangement mode 2 is the best to control the deflection force effectively.

According to the above-mentioned analysis, considering deflection, vibration, and deflection force synthetically, the stabilizer that was arranged every five drill-rod section intervals can restrain the inconsistent movement between 

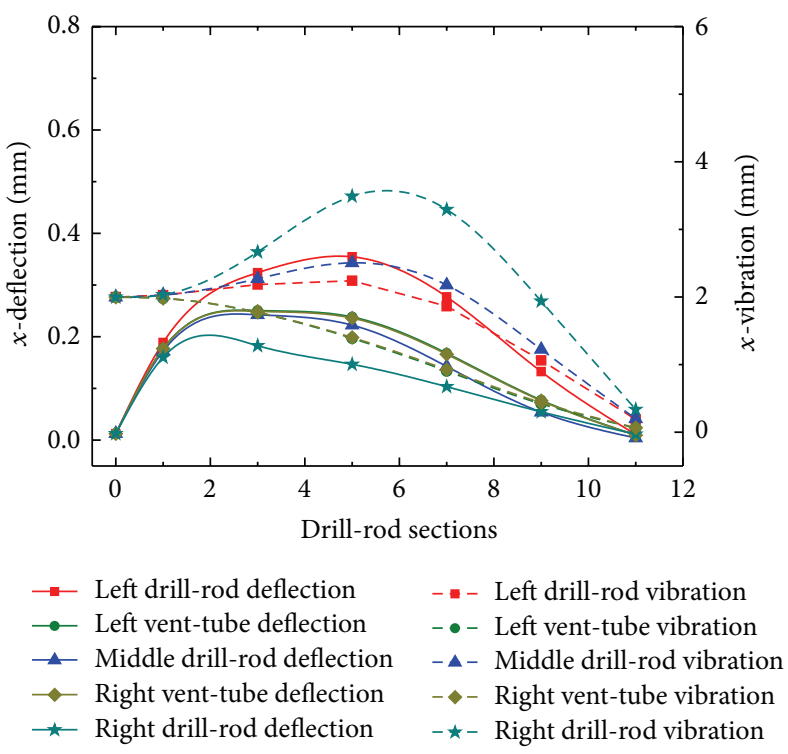

(a)
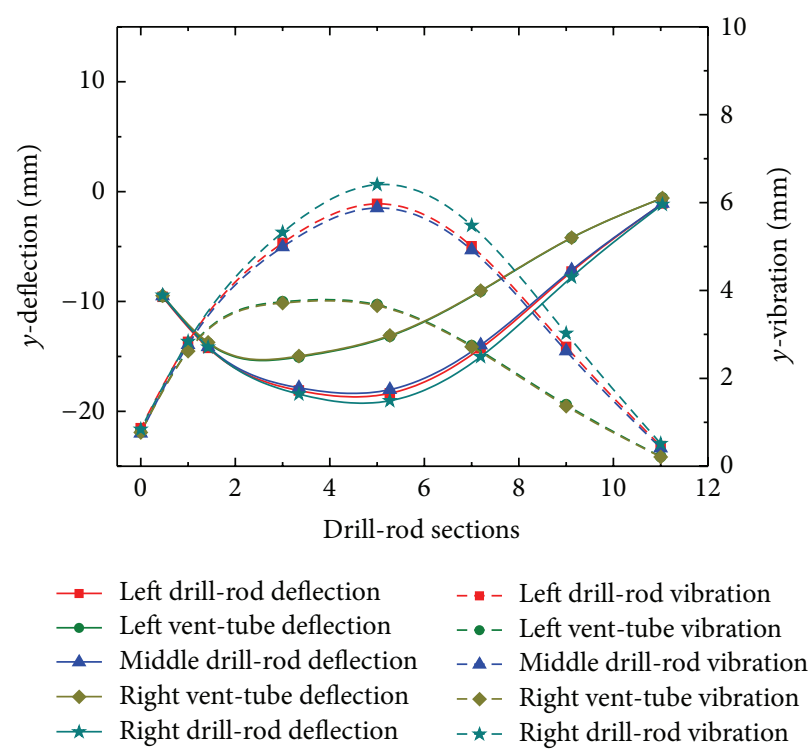

(b)

FIGURE 17: Vibration and deflection of the working mechanism (bits A and C subjected complex load).

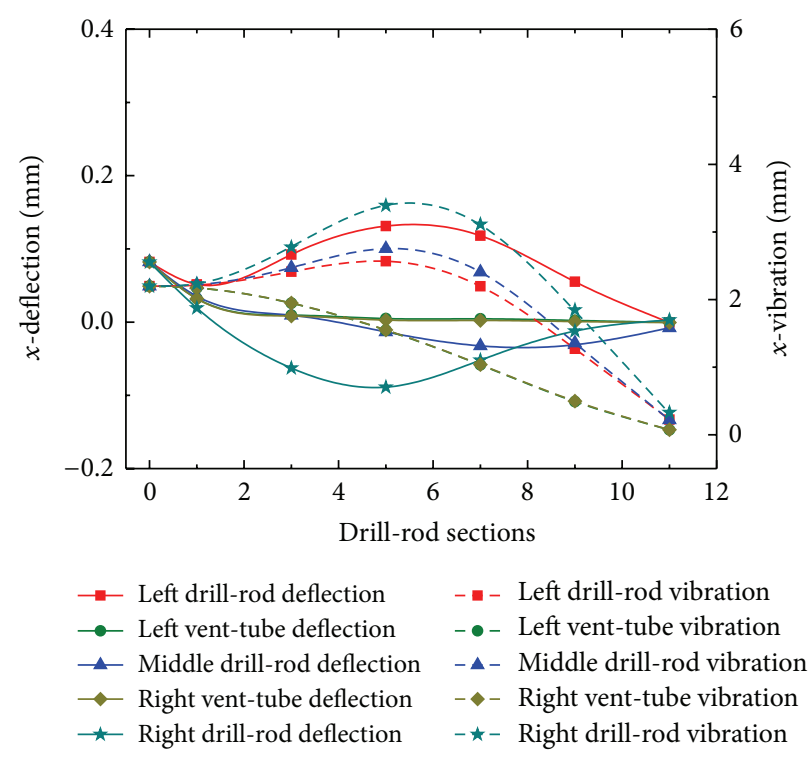

(a)

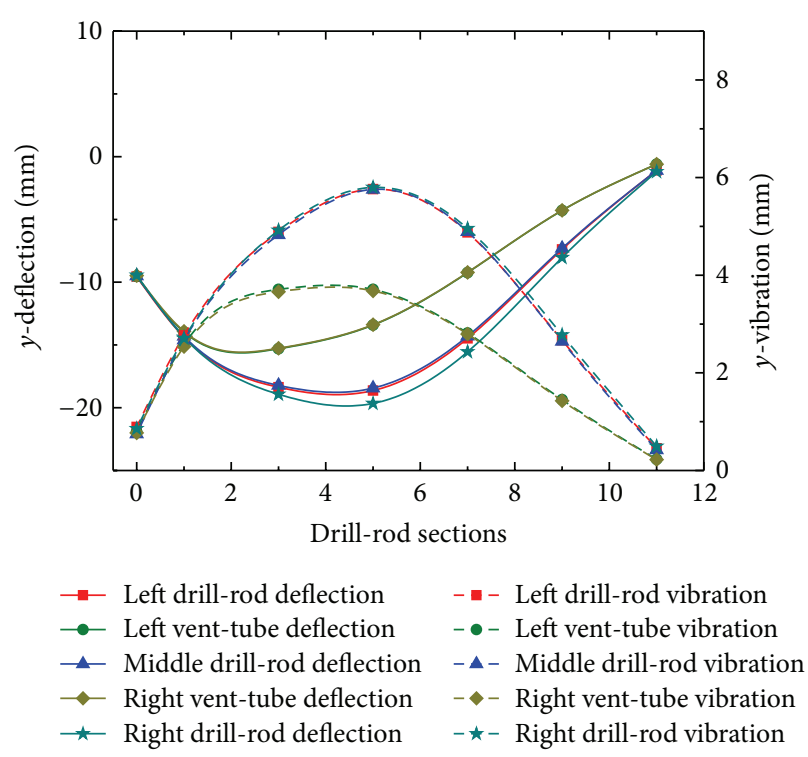

(b)

FIGURE 18: Vibration and deflection of the working mechanism (bits A, C, and E subjected complex load).

the drill-rods and vent-tubes effectively. This can improve the overall deflection resistance performance and stability significantly.

\section{Conclusion}

(1) A drilling test bed of the working mechanism was built, and vibration, drilling torque, and propulsion resistance were measured. Experiment results show that the vibration and deflection increase with drilling depth in the $x$ direction but increase first and then gradually become stable in the $y$ direction, which makes the coal and rock become more difficult to be cut. Similarly, the vibration and deflection are greater under partial load. Reasonable stabilizer arrangement can effectively reduce deflection and vibration of the working mechanism.

(2) A rigid-flexible coupling simulation model of a fivedrill-bit coal auger working mechanism was established, and vibration and deflection under different 


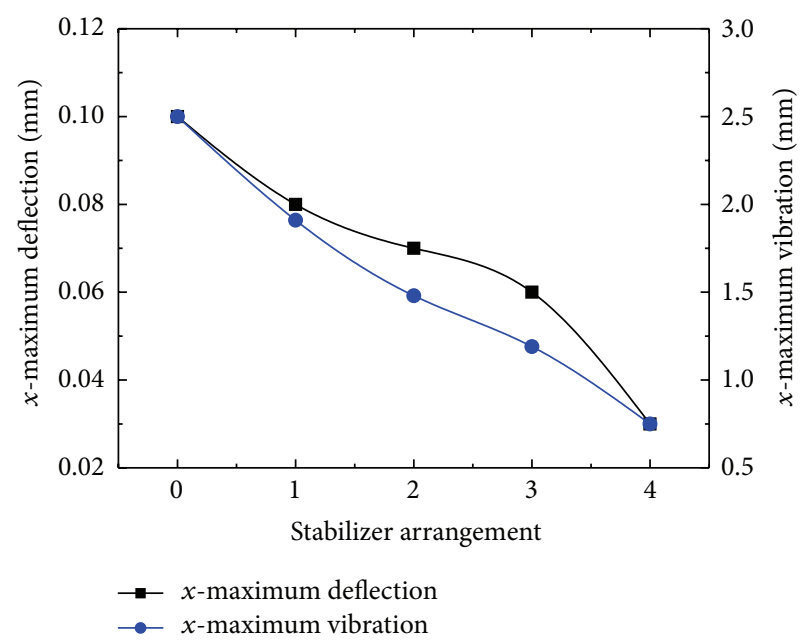

(a)

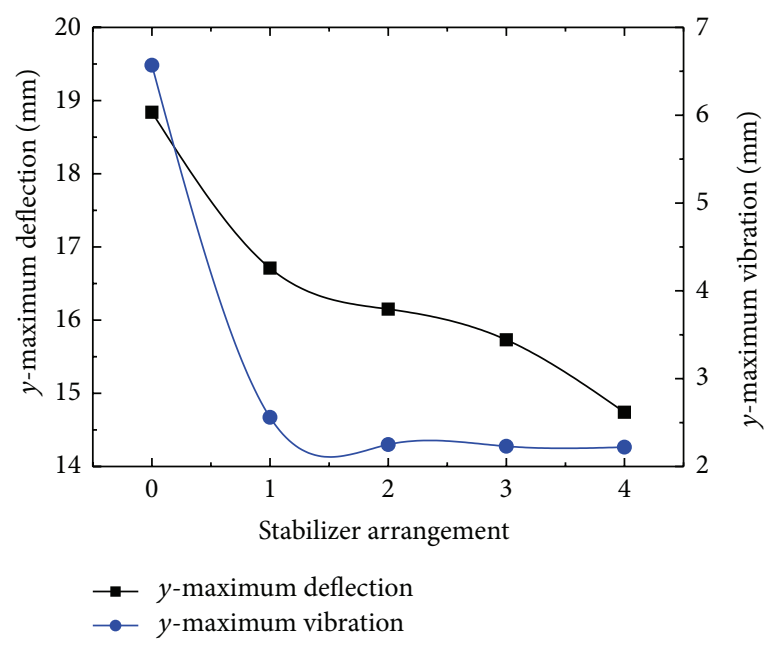

(b)

FIGURE 19: Law of maximum vibration and deflection under different stabilizer arrangements.

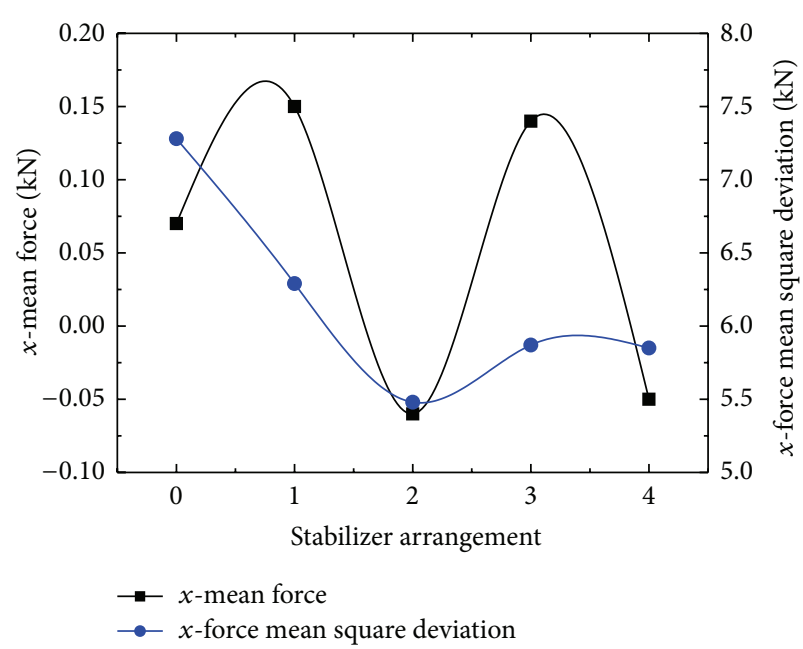

(a)

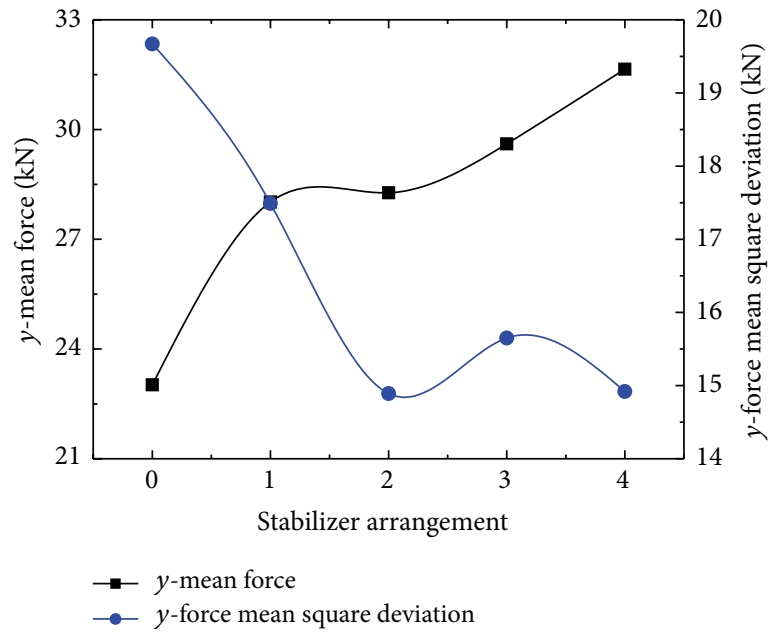

(b)

FIGURE 20: Law of deflection force under different stabilizer arrangements.

conditions were researched. The results show that the vibration and deflection under different conditions change in the same manner as the simulation results. This means that the simulation results are agreeable. Moreover, the vibration and deflection also increase with partial load. By arranging the stabilizer at every five drill-rod section intervals, the vibration and deflection can be decreased by $30 \%$ and $40 \%$ in the $x$ direction and $14.3 \%$ and $65.7 \%$ in the $y$ direction, respectively.

(3) Increasing drilling depth blindly not only decreases the drilling efficiency but also increases the vibration of the working mechanism and energy loss. Power equilibrium of drill-bit is good for enhancing antipartial performance of the working mechanism.

\section{Conflict of Interests}

The authors declare that there is no conflict of interests regarding the publication of this paper.

\section{Acknowledgments}

The authors acknowledge Special Foundation for the Fundamental Research Funds for the Central Universities, China (Grant no. 2014ZDPY12), and the Priority Academic Program Development of Jiangsu High Education Institute of China. 


\section{References}

[1] J. P. Li, C. L. Du, and Y. Z. Zhang, "Present status and development tendency of mining equipment for thin and ultrathin seam in China," Coal Science and Technology, vol. 33, no. 6, pp. 65-67, 2005.

[2] X. X. Cui, H. F. Ji, M. X. Lin, and Z. A. Dong, "Vibration characteristic analysis of the multi-drilling mechanism," Journal of Vibroengineering, vol. 16, no. 6, pp. 2722-2734, 2014.

[3] L. Fu, C. L. Du, and H. X. Jiang, "Simulation study of arrangement modes of stabilizers in auger miners," Mining \& Processing Equipment, vol. 40, no. 9, pp. 20-24, 2012.

[4] K. K. Millheim and M. C. Apostal, "The effect of bottomhole assembly dynamics on the trajectory of a bit," Journal of Petroleum Technology, vol. 33, no. 12, pp. 2323-2338, 1981.

[5] K. A. Macdonald and J. V. Bjune, "Failure analysis of drillstrings," Engineering Failure Analysis, vol. 14, no. 8, pp. 16411666, 2007.

[6] C.-Y. Kuang, Z.-B. Wu, and D.-K. Ma, "Lateral vibration dynamic simulation model of cone bit," China Petroleum Machinery, vol. 27, no. 1-2, pp. 7-8, 1999.

[7] C.-Y. Kuang, D.-K. Ma, Q. Y. Liu, and Z.-B. Wu, “The drill string-bit-rock system dynamic behavior simulation," Acta Petrolei Sinica, vol. 22, no. 3, pp. 81-85, 2001.

[8] Y. A. Khulief and H. Al-Naser, "Finite element dynamic analysis of drillstrings," Finite Elements in Analysis and Design, vol. 41, no. 13, pp. 1270-1288, 2005.

[9] Y. A. Khulief, F. A. Al-Sulaiman, and S. Bashmal, "Vibration analysis of drillstrings with self-excited stick-slip oscillations," Journal of Sound and Vibration, vol. 299, no. 3, pp. 540-558, 2007.

[10] X.-X. Cui and C.-J. Tan, "Coupling vibration of a drilling system with interaction between drilling mechanism and coal rock," Journal of Vibration and Shock, vol. 33, no. 16, pp. 97-104, 2014.

[11] G. C. Downton, "Directional drilling system response and stability," in Proceedings of the 16th IEEE International Conference on Control Applications (CCA '07), pp. 1543-1550, IEEE, Singapore, October 2007.

[12] M. Bairdes, "Static and dynamic tridimensional BHA computer models," in Proceedings of the 16th IEEE International Conference on Control Applications, vol. 3, pp. 1569-1576, Singapore, 2007.

[13] E. M. Navarro-López and D. Cortés, "Avoiding harmful oscillations in a drillstring through dynamical analysis," Journal of Sound and Vibration, vol. 307, no. 1-2, pp. 152-171, 2007.

[14] E. M. Navarro-López, "An alternative characterization of bitsticking phenomena in a multi-degree-of-freedom controlled drillstring," Nonlinear Analysis: Real World Applications, vol. 10, no. 5, pp. 3162-3174, 2009.

[15] H. Hakimi and S. Moradi, "Drillstring vibration analysis using differential quadrature method," Journal of Petroleum Science and Engineering, vol. 70, no. 3-4, pp. 235-242, 2010.

[16] S. M. Sahebkar, M. R. Ghazavi, S. E. Khadem, and M. H. Ghayesh, "Nonlinear vibration analysis of an axially moving drillstring system with time dependent axial load and axial velocity in inclined well," Mechanism and Machine Theory, vol. 46, no. 5, pp. 743-760, 2011.

[17] M. Z. Jiang, K. X. Dong, and M. Xin, "Dynamic instability of slender sucker rod string vibration characteristic research," Advanced Materials Research, vol. 5, no. 50, pp. 3173-3179, 2012.
[18] Q. Sun and C.-C. Guan, "A method of determine dynamic stability critical length of construction member," Applied Mechanics and Materials, vol. 16, no. 6, pp. 3306-3310, 2012.

[19] Y. Kovalyshen, "A simple model of bit whirl for deep drilling applications," Journal of Sound and Vibration, vol. 332, no. 24, pp. 6321-6334, 2013.

[20] S. Y. Liu, X. X. Cui, and X. H. Liu, "Coupling vibration analysis of auger drilling system," Journal of Vibroengineering, vol. 15, no. 3, pp. 1442-1453, 2013.

[21] J. M. Kamel and A. Yigit, "Modeling and analysis of axial and torsional vibrations of drill strings with drag bits," in Proceedings of the International Petroleum Technology Conference, vol. 12, pp. 549-560, Society of Petroleum Engineers, Doha, Qatar, January 2014.

[22] J. Xu, Y. Xu, and J. C. Li, "Fatigue life analysis of auger stem in soft coal seam," Applied Mechanics and Materials, vol. 472, no. 2, pp. 111-114, 2014. 


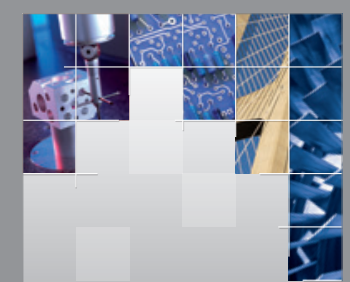

\section{Enfincering}
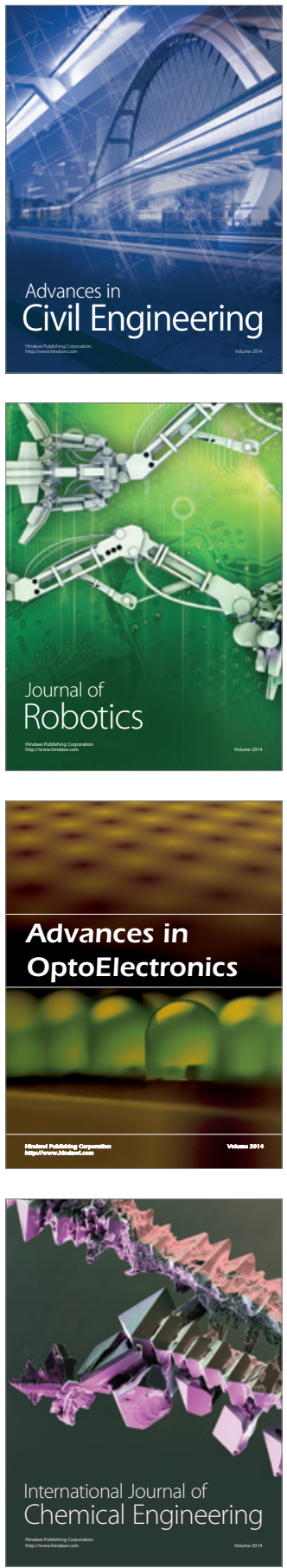

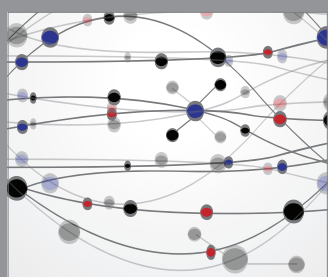

The Scientific World Journal

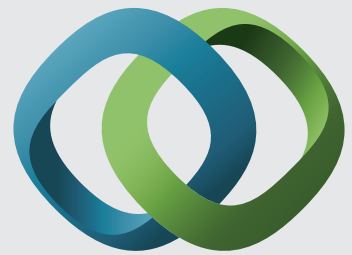

\section{Hindawi}

Submit your manuscripts at

http://www.hindawi.com
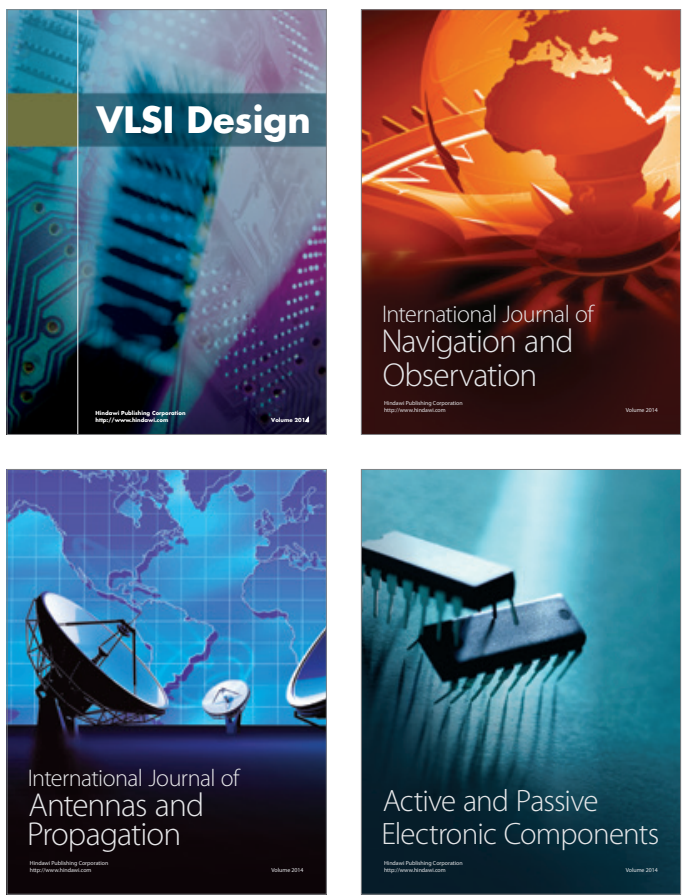
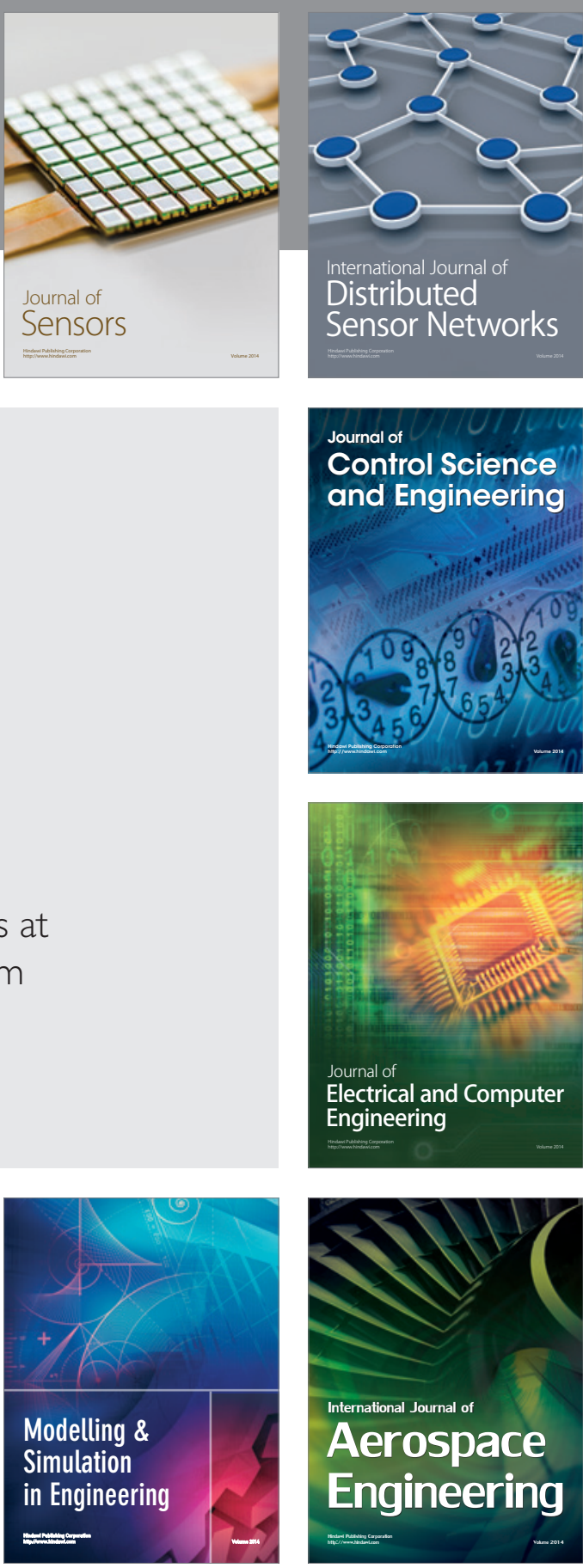

International Journal of

Distributed

Sensor Networks

Journal of

Control Science

and Engineering
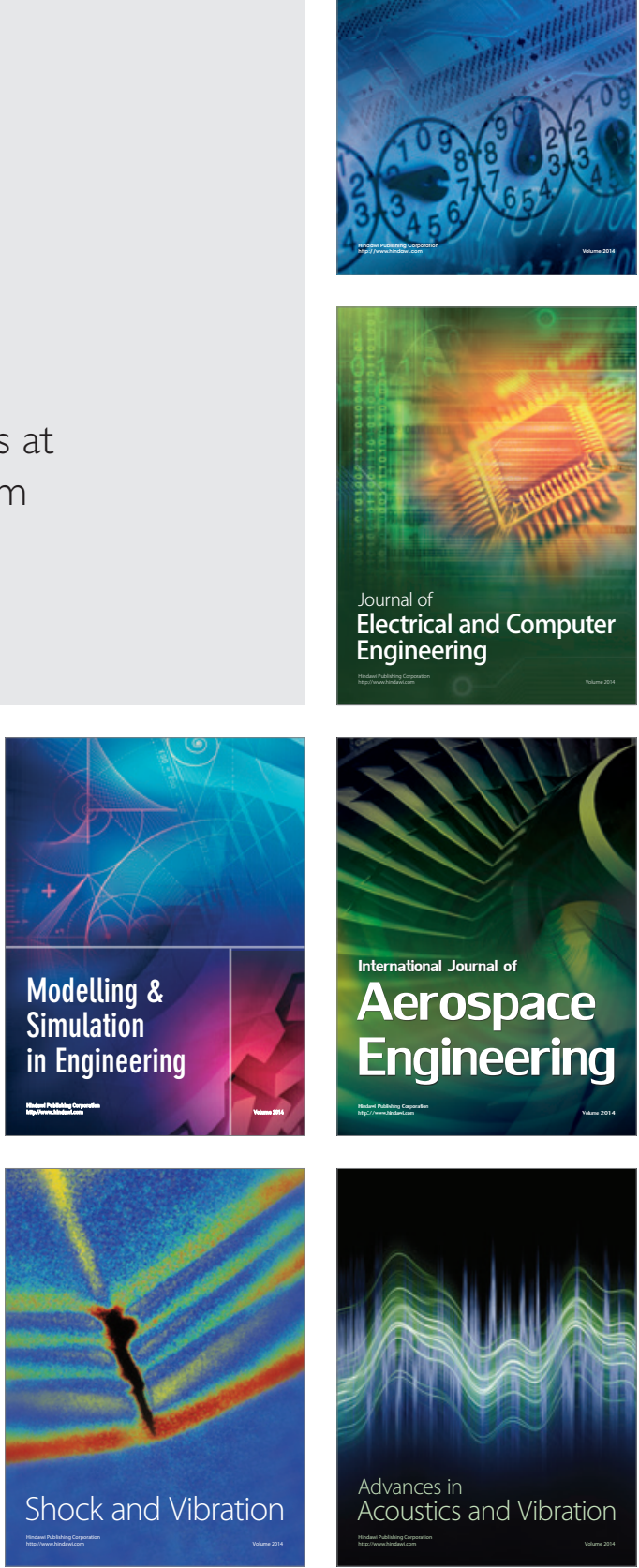